\title{
TOWARD A TAXONOMY OF PROJECTIVE CONTENT
}

JUDITH TONHAUSER

The Ohio State University

Craige RoBerts

The Ohio State University
DAVID BEAVER

University of Texas at Austin

MANDY SIMONS

Carnegie Mellon University

Projective contents, which include presuppositional inferences and Potts's (2005) conventional implicatures, are contents that may project when a construction is embedded, as standardly identified by the FAMILY-OF-SENTENCES diagnostic (e.g. Chierchia \& McConnell-Ginet 1990). This article establishes distinctions among projective contents on the basis of a series of diagnostics, including a variant of the family-of-sentences diagnostic, that can be applied with linguistically untrained consultants in the field and the laboratory. These diagnostics are intended to serve as part of a toolkit for exploring projective contents across languages, thus allowing generalizations to be examined and validated crosslinguistically. We apply the diagnostics in two languages, focusing on Paraguayan Guaraní (Tupí-Guaraní), and comparing the results to those for English. Our study of Paraguayan Guaraní is the first systematic exploration of projective content in a language other than English. Based on the application of our diagnostics to a wide range of constructions, four subclasses of projective contents emerge. The resulting taxonomy of projective content has strong implications for contemporary theories of projection (e.g. Karttunen 1974, Heim 1983, van der Sandt 1992, Potts 2005, Schlenker 2009), which were developed for the projective properties of particular subclasses and fail to generalize to the full set of projective contents.*

Keywords: projective contents, felicity constraints, local effect, Paraguayan Guaraní, crosslinguistically applicable diagnostics

1. INTRODUCTION: PROJECTIVE CONTENT AS A DOMAIN FOR CROSSLINGUISTIC STUDY. The goal of this article is to establish distinctions among a range of inferential phenomena that have in common the property of PROJECTION, the term originating in Langendoen \& Savin 1971. Projection concerns implications associated with particular words, constructions, and utterances, so-called TRIGGERS (where the term IMPLICATION is neutral between assertion, entailment, conversational implicature, etc.). What is notable about these implications is that they tend to survive - that is, they tend to be understood as commitments of the speaker - even when the trigger is embedded under operators that usually block the implications of material in their scope. ${ }^{1}$ Projection is typically diagnosed using the FAMILY-OF-SENTENCES diagnostic (Chierchia \& McConnell-Ginet 1990:29f.), illustrated with the examples in 1.

* For helpful feedback and discussions, we thank Jefferson Barlew, Chris Barker, Maria Bittner, Lucas Champollion, Kai von Fintel, Mira Grubic, Lisa Matthewson, E. Allyn Smith, Daniel Velleman, an anonymous referee for Language, our associate editor Jürgen Bohnemeyer, and the participants in the three workshops on Projection, Entailment, Presupposition and Assertion (PEPA) in Columbus, Ohio (2009), Vancouver, Canada (2010), and Rutgers, New Jersey (2011), the participants of the 2011 ESSLLI course on projective content, and the audiences at a colloquium at the University of Tübingen in June 2011, at the 2011 annual meeting of the Linguistic Society of America, and at Semantics of Under-represented Languages in the Americas (SULA) 6. We also thank our Paraguayan Guaraní language consultants for working with us, especially Marité Maldonado, Evert Ojeda Morán, and Julio Rolon. This project is financially supported by a collaborative research grant from the National Science Foundation to David Beaver, Craige Roberts, Mandy Simons, and Judith Tonhauser ('Collaborative Research: Semantics and Pragmatics of Projective Meaning across Languages'; grants BCS-0952571 (OSU), BCS-0952497 (CMU), BCS-0952862 (UT Austin); 2010-2012). Beaver was additionally supported by NSF grant BCS-0904913.

${ }^{1}$ Projective contents are understood as commitments of the speaker only if they project globally. For simplicity, we set aside cases in which a projective content is contributed to a nonglobal local context; see the discussion of intermediate accommodation in, for example, van der Sandt 1992 and Beaver 2001:Ch. 5. 
(1) Chierchia \& McConnell-Ginet 1990:28

a. The present queen of France lives in Ithaca.

b. It is not the case that the present queen of France lives in Ithaca.

c. Does the present queen of France live in Ithaca?

d. If the present queen of France lives in Ithaca, she has probably met Nelly. In this illustration, we observe the behavior of the implication that there is a unique queen of France, which is triggered by the use of the definite the present queen of France. An utterance of sentence 1a entails both that there is a unique queen of France and that she lives in Ithaca. Utterances of the sentences $1 \mathrm{~b}-\mathrm{d}$ do not entail that anyone lives in Ithaca, but do still, under normal circumstances, commit the speaker to the claim that France has a unique queen. We call this behavior of the existence implication 'projection' and call this implication a PROJECTIVE CONTENT: a content that has the potential to project.

The range of constructions associated with implications that exhibit projective behavior is huge. It includes all implications standardly analyzed as presuppositions or as conventional implicatures (and this whether the term is used in the sense of Grice 1975 or that of Potts 2005). We argue in this article that projective content is divided into four subclasses, summarized in Table 1. These subclasses are distinguished by two properties that a projective implication may have: (i) being subject to a STRONG CONTEXTUAL FELICITY constraint, and (ii) giving rise to OBLIGATORY LOCAL EFFECT. Strong contextual felicity refers to a particular condition on the felicitous use of a trigger, namely, that it can be used felicitously only if some implication associated with the trigger is established in the utterance context. This property is discussed in detail in $\S 3$. Obligatory local effect refers to the way in which a triggered implication interacts with operators: some part of the content of a clause embedded under an operator is said to have obligatory local effect just in case it is necessarily part of the content that serves as the operator's semantic scope. For detailed discussion of this property, see $\S 5$.

\begin{tabular}{cccc} 
& \multicolumn{3}{c}{ PROPERTIES OF CONTENTS } \\
CLASSES & PROJECTION & CONTEXTUAL FELICITY & OBLIGATORY \\
A & yes & yes & yes \\
B & yes & no & no \\
C & yes & no & yes \\
D & yes & yes & no
\end{tabular}

TABLE 1. Four classes of projective content in English and Paraguayan Guaraní.

As seen in Table 1, projective contents in class A are associated with a strong contextual felicity constraint and have obligatory local effect, class B projective contents are not associated with a strong contextual felicity constraint and do not have obligatory local effect, class $\mathrm{C}$ projective contents are not associated with a strong contextual felicity constraint but have obligatory local effect, and class D projective contents are associated with a strong contextual felicity constraint but do not have obligatory local effect. Broadly speaking, classes A and D include certain implications of anaphoric and indexical triggers, class B includes Potts's (2005) conventional implicatures, but also some contents associated with indexical and anaphoric expressions, and class $\mathrm{C}$ includes a mixture of cases standardly described as presuppositions, including factivity, along with implications whose analysis is more controversial, such as those associated with approximatives (e.g. almost) and exclusives (e.g. only). We show below that classes A, B, and $\mathrm{C}$ echo commonly made distinctions among projective contents, and yet subtly 
cross-cut them, while class $\mathrm{D}$ is, we believe, a previously unrecognized class of projective content.

Early observations about projection identified it as a property of presuppositional content, and projection has subsequently been studied almost entirely from this perspective. In more recent work, however, the close identification of presupposition with projection has been undermined. Chierchia and McConnell-Ginet (1990:351) observe that the content of English nonrestrictive relative clauses projects, but hesitate to call this content presuppositional because it does not seem to be subject to any requirement to be background for the addressee. Beaver (2001) comes to similar conclusions regarding English parentheticals. And Potts (2005) takes robust projection behavior to be a core property of the components of meaning he classes as conventional implicatures (including implications triggered by parentheticals, expressives, and honorifics), while at the same time arguing that conventional implicatures are not presuppositions. These observations constitute a serious challenge to most existing accounts of projection, such as Heim 1983, van der Sandt 1992, and Schlenker 2007, as these are all predicated on the assumption that projection is a consequence of the presuppositional status of the relevant implication. (See $\S 8$ and Simons et al. 2011 for further discussion.)

The fact that all of the types of implications discussed in detail in this article share the property of projectivity provides a rather obvious motivation for studying them together. $^{2}$ The strategy that we have chosen for the study of this class of contents - a strategy whose utility is demonstrated by the results reported in this article-involves careful investigation of the linguistic behavior of a wide range of triggers of projective content. A theoretical account is, after all, unlikely to be successful unless it is founded on a robust grasp of the phenomenon to be explained. We suggest that in order to achieve an adequately robust understanding, we need to examine projection not only in English (as has typically been the case), ${ }^{3}$ but in other languages too. And we need reliable data based not only on the judgments of theoreticians, but also on the linguistic judgments of theoretically untrained native-speaker consultants.

These desiderata raise some interesting challenges at the interface of theory and methodology. Theoreticians tend to take a 'we know it when we see it' approach to projection. But if projection is to be diagnosed by judgments rendered by consultants in the field or by subjects in the lab, we need to determine exactly which judgments are relevant, and we need a strategy to elicit these judgments reliably. Similar issues arise for the identification of the strong contextual felicity constraint and obligatory local effect, which distinguish among subclasses of projective contents.

One goal of this article, therefore, is to put the study of projection on a sounder empirical footing. We propose here an extension of the standard empirical paradigm of constructed examples that is appropriate for crosslinguistic work with consultants who have no specific training in linguistics. To be clear, we do not wish to make any deep philosophical point about what constitutes sound methodology. Or perhaps it would be more appropriate to say that to the extent that we make a methodological point, we make it primarily by doing rather than saying. Thus the bulk of this article is taken up not with meta-discussion about the nature of data collection, but with description and

${ }^{2}$ Projectivity is almost certainly not the only property that these implications share. Based on work on English (Simons et al. 2011), we have found what we take to be compelling evidence of a relationship between projection and AT-ISSUENESS, with Jayez (2009) and Tonhauser (2012) providing crosslinguistic support from French and Paraguayan Guaraní (Tupí-Guaraní), respectively.

${ }^{3}$ Some research has been carried out on the related topic of presupposition in languages other than English by, for example, Levinson and Annamalai (1992) on Tamil and Matthewson (2006) on St'át'imcets (Salish). 
explanation of the development and application of specific diagnostic methods that we have applied in two typologically unrelated languages, English and Paraguayan Guaraní (Tupí-Guaraní).

The significance of providing a crosslinguistic foundation for empirical work on presupposition, and projective contents more generally, is highlighted by recent work of Matthewson (2006). On the basis of fieldwork on St'át'imcets (Salish), she draws the striking conclusion that St'át'imcets presuppositions do not impose a constraint on the common ground and are informative (see also e.g. Matthewson 1998, 2008 on presuppositions triggered by St'át'imcets determiners and pronouns). Since she assumes that presuppositions in English involve common-ground constraints (Stalnaker 1973, 1974), she concludes that there is a significant difference between presuppositions in English and in St'át'imcets, and argues against strong presuppositional universals. The empirical domain we consider in this article is considerably wider than Matthewson's, as it includes English and Guaraní triggers of projective contents not associated with a commonground constraint. The results we report on point in a different direction from Matthewson's since, in terms of the diagnostics we use, our results indicate that the two languages we studied are similar. It would be surprising to find such strong similarities between typologically unrelated languages, if there were not strong universal tendencies among standard presuppositions, and other types of projective content as well.

We thus hope to make contributions on several fronts in this article. First, the work is relevant to researchers in formal semantics and pragmatics for its arguments that projective content is heterogeneous in ways not currently appreciated, ways that have important consequences for theories of projection. Second, the diagnostics, and the methodology that underlies them, may be of interest to fieldworkers and to anyone interested in collection of data from nonlinguist language consultants, in the field or in the laboratory. Finally, the article makes a modest contribution to semantic typology, containing the first analysis of a wide range of projective contents in a non-European language.

The article proceeds as follows. We first provide some background on the development of the diagnostics used in this article and introduce the triggers of projective content of Guaraní to be explored (§2). Diagnostics for exploring strong contextual felicity, projection, and obligatory local effect, respectively, are then illustrated in $\S \S 3-5$, and we motivate why diagnosing strong contextual felicity prior to projection is necessary in $\S 4$. Class D of projective contents is separately diagnosed and discussed ( $\$ 6)$, and we then present in $\$ 7$ a summary of the empirical findings in an expanded version of Table 1 and characterize the classes A, B, C, and D of projective content and their relationship to previously characterized meaning types, such as classical presuppositions and Potts's conventional implicatures. As discussed in the final section, the taxonomy of projective content that empirically emerges in the two languages has strong implications for contemporary theories of projection (e.g. Karttunen 1974, Heim 1983, van der Sandt 1992, Potts 2005, Schlenker 2009), which were developed for the projective properties of subclasses, and which fail to generalize to the full set of projective contents.

2. PARAguayan GUARANí tRIGgers AND CRITERIA FOR DiagnOSTICS. The choice of English and of Guaraní for the detailed study of projection is not motivated by any special properties of the languages. English is the native language of three of the four authors and has been the focus of the vast majority of work to date on presupposition and projection. The first author of the article has extensive (though nonnative) knowledge of Guaraní and experience conducting fieldwork in this language. In general, exploring meaning in collaboration with linguistically untrained native-speaker consultants re- 
quires that the fieldworker have knowledge of a wide range of grammatical structures of the language, including phonological, morphological, syntactic, and pragmatic factors that affect whether an expression is grammatical and felicitous in a particular context (see also Matthewson 2004:370). The utterances to be judged must be grammatical since otherwise a consultant might reject the utterance in a context not because it is false or infelicitous but simply because it is ungrammatical (Matthewson 2004:386, 401). And to be judged acceptable, utterances must be presented in discourse contexts that appropriately control for the relevant contextual factors.

Guaraní is unusual among South American indigenous languages, not just because it is widely spoken (by about four million people in Paraguay and surrounding countries), but also because it is fairly well documented. In addition to reference works (Gregores \& Suárez 1967, Velázquez-Castillo 2004a), there are papers and books on the phonetics and phonology of the language (e.g. Lunt 1973, Rivas 1974, Adelaar 1994, Walker 1999), its morphosyntax (e.g. Velázquez-Castillo 1996, 1999, 2002a,b, 2004b, Nordhoff 2004), word order and argument marking (e.g. Velázquez-Castillo 1995, Shain \& Tonhauser 2010, Tonhauser \& Colijn 2010), and its prosody (Clopper \& Tonhauser 2011, 2013), as well as its temporal, aspectual, and modal system (e.g. Liuzzi 1987, Liuzzi \& Kirtchuk 1989, Dessaint 1996, Tonhauser 2006, 2007, 2009, 2010, 2011a,b). Exploring projective contents in Guaraní in collaboration with native-speaker consultants is greatly facilitated by this wealth of information already available on the language.

Our goal in developing the diagnostics used here was not to devise methods specifically for the study of Guaraní, or of English, but to develop a toolkit that can be adapted for use with different languages and also in different settings (e.g. in fieldwork with individual consultants and also in experimental settings). This required the diagnostics to be formulated as independently as possible from any language-particular lexical inventory or (morpho)syntactic constructions, so as to be applicable in a typologically diverse range of languages and thus to facilitate crosslinguistic comparison of projective contents. A diagnostic that would fail in this respect is one that, for example, requires forming sentences with negated auxiliary verbs: since many languages, including Guaraní, do not have such verbs, such a diagnostic would not be crosslinguistically applicable. In combination with this flexibility, however, we have attempted to present the diagnostics in adequate detail so as to make it possible to derive comparable crosslinguistic results.

A second critical desideratum for the diagnostics was that they should rely only on judgments by linguistically untrained native-speaker consultants that can be reliably obtained; that is, consultants should understand the task the diagnostic asks them to perform and the task should be natural. Third, in keeping with standard practice in experimental design, the diagnostics should be formulated in such a way that they do not bias consultants toward a particular answer.

The empirical generalizations presented in this article are based on judgments elicited from four native speakers of Guaraní, who are also fluent in Spanish. The main consultant was a woman in her early fifties from the capital, Asunción, who is equally comfortable speaking Guaraní and Spanish. Her judgments on a large variety of data elicited over the course of the four years (2009 to 2012) during which this work was carried out form the basis for the empirical generalizations presented here. The other three consultants were two men in their early twenties from the department of Guairá and a woman in her thirties from the capital, all of whom report being more comfortable speaking Guaraní than Spanish. The data in $\S \S 4$ and 5 are based only on judgments by 
the main consultant and the two men due to the unavailability of the fourth consultant. Disagreeing judgments were rare, but are noted with the relevant examples.

The diagnostics for strong contextual felicity and obligatory local effect developed in $\S \S 3$ and 5, respectively, rely on judgments of the acceptability of grammatical sentences in context (see Matthewson 2004 for an overview and discussion of judgments obtainable from linguistically untrained language consultants). ${ }^{4}$ The diagnostic for projection developed in $\S 4$ relies on acceptability judgments and also on what we call IMPLICATION JUDGMENTS. That is, the diagnostic involves obtaining judgments from a consultant that provide clues about whether a given utterance in a particular context gives rise to a target implication. It is a task for the linguist to determine the proper analysis of a given implication. However, we take it that the identification of the presence of an implication is a basic data point with respect to which speakers can be expected to have judgments. Indeed, such judgments have already been successfully used in experimental research on scalar implicatures (e.g. Geurts et al. 2010) and presuppositions (e.g. Schwarz 2007, Beaver \& Clark 2008, Chemla 2009), where a common paradigm is to ask linguistically untrained participants to assess whether an utterance has a particular implication or which of a given set of implications an utterance has.

Since asking a consultant whether a particular utterance gives rise to a particular implication may constitute a leading question, we avoid directly eliciting implication judgments, and instead make use of what we call INDIRECT IMPLICATION JUDGMENTS. In such judgment tasks, speakers are asked a question that is unrelated to the target implication, but the answer to which allows the fieldworker to determine whether the target implication arises from the utterance or not. Particularly useful are contexts where indirect implication judgments are based on the goals or desires of a rational agent. To illustrate, consider the example in 2: the context of this example presents Maria as having a particular goal, namely to interview people who had a near-death experience. Rather than asking a consultant whether 2 implies that Raul came close to dying, a consultant is asked whether Maria would interview Raul, given Paula's utterance.

(2) [Context: Maria wants to interview people who had a near-death experience. Paula tells her about her neighbor Raul. $]^{5}$

Raul aimete o-mano.

Raul almost A3-die

'Raul almost died.'

\footnotetext{
${ }^{4}$ In the first author's fieldwork on Guaraní, contexts are typically presented verbally either in Guaraní or in Spanish (see Matthewson 2004 for the appropriateness of using a metalanguage to present contexts).

${ }^{5}$ The Guaraní examples in this article are given in the standardized orthography of the language used in Paraguay (Ministerio de Educación y Cultura 2004, Velázquez-Castillo 2004a:1421f.), except that all postpositions are attached to their host. Following this orthography, stressed oral syllables are marked with an acute accent and stressed nasal syllables are marked with a tilde; acute accents are not written for normally accented words (stress on the final syllable). The set A cross-reference prefixes (which mark transitive subjects and some intransitive subjects) are $a(i)$ - 'A1SG', ja(i)- 'A1PL.INCL', ro(i)- 'A1PL.EXCL', re(i)- 'A2sG', pe(i)'A2PL', and $o(i)-$ 'A3'; the set B prefixes (which mark some intransitive subjects and possessors) are $c h e(r)$ 'B1SG', nande(r)- 'B1PL.INCL', ore (r)- 'B1PL.EXCL', nde(r)- 'B2SG', pende(r)- 'B2PL', and $i(\tilde{n})-/ h-$ 'B3'. The two portmanteau prefixes ro(i)- ' $1 / 2 \mathrm{SG}$ ' and $p o(i)$ - '1/2PL' refer to a first-person subject and a second-person (singular/plural) object. The following glosses are used: ABL: ablative, CAUS: causative, COMPL: completive aspect, CONTR: contrastive topic, DES: desiderative modal, DIM: diminutive, EXCL: exclusive, INCL: inclusive, JE: middle/passive, MIGHT: possibility modal, MUST: necessity modal, NEG: negation, NOM: nominalization, PART: particle, PRF: perfect aspect, PURP: purpose, PRON.O/S: object/subject pronoun, PROSP: prospective aspect/modal, TERM: terminative aspect, Q: question, RC: relative clause.
} 
If a consultant affirms that, yes, Maria would want to interview Raul, this can be taken as evidence that 2 conveys that Raul came close to dying and thus as evidence for the hypothesis that the adverb aimete 'almost' contributes a proximal implication in this particular utterance.

Having laid out the basics of our methodology, we turn now to an overview of the Guaraní expressions that are investigated in this article. These are primarily translations of expressions in English that trigger projective contents, including pronouns, possessive and demonstrative noun phrases, change-of-state verbs, the additive adverb too, and the factive verb know. Possible translations were straightforwardly identified by elicitation and using dictionaries, except in the case of the change-of-state verb stop: translations of English utterances like Juan stopped smoking first resulted in Guaraní translations with the verb (o)heja 'leave' and the nominalized argument la jepita 'the smoke', as in 3a. While this construction triggers projective content, it did not turn out to be productive, as it was not used to express changes of state with other predicates. It was thus replaced in subsequent fieldwork with the construction $n(d)(a)-\ldots-v e ́-i-m a$ (NEG-...-more-NEG-PRF) 'not anymore'. Like its English translation, the utterance in 3b implies that Juan used to smoke in the past (the PRESTATE implication) but has ceased to smoke (as shown in $\S \S 3$ and 4).

(3) a. Juan o-heja la jepita. Juan A3-leave the smoke

'Juan stopped smoking.' (lit. 'John left the smoke.')

b. Juan nd-o-pita-vé-i-ma.

Juan NEG-A3-smoke-more-NEG-PRF

'Juan does not smoke anymore.'

In addition to the projective content of the change-of-state expression $n(d)(a)-\ldots-v e$ $i$-ma 'not anymore' introduced in $3 \mathrm{~b}, \S \S 3$ to 5 explore properties of the projective contents of the Guaraní expressions illustrated in the examples in 4 to 9. We focus here on presenting the relevant expressions and their projective implications, and postpone supporting the claim that the Guaraní expressions give rise to projective implications with different properties to the next sections. All implications of the relevant Guarani expressions are characterized as propositions, as opposed to characterizing some as constraints on context as is common in the literature on English projective contents (see n. 9 for discussion).

The verb (oi)kuaa 'know' embeds a sentential complement, which is marked on the embedded verb by the nominalizing suffix $-h a$. We explore the properties of the content of the complement clause.

(4) [Context: A family receives a young man who has returned to their town after many years away.]

Roi-kuaa niko re-ju-ha-gue.

A1PL.EXCL-know PART A2SG-Come-NOM-NOM.TERM

'We knew that you had come.'

(from a theater play)

The naturally occurring examples in 5 feature the adverb avei 'too', the adverb aimete 'almost', and the suffix -nte 'only', respectively. The adverb avei 'too' occurs in 5 a after the noun phrase vúrro tuja have 'very old donkey'. With avei 'too', we explore the properties of the implication that there is an alternative true proposition (the EXISTENCE implication), that is, the implication that there is another individual satisfying the relevant predication: in 5a, this is the implication that there was another individual running down the path. We also explore the properties of the implication that this alterna- 
tive proposition is salient (the SALIENCE implication). In the context of 5a, the contextually salient alternative true proposition is that expressed by the first conjunct, namely that the jaguar ran down the path. The adverb aimete 'almost' in $5 \mathrm{~b}$ conveys that the brother came close to falling onto the spines of the coconut plant, but ultimately did not (the POLAR implication, which we show to be projective, but see e.g. Horn 2002 for an alternative position). And the suffix -nte 'only' in 5c conveys that the head of the monkey was sticking out of the hole in the tree (the PREJACENT implication) and that it was the only body part that was sticking out (see also Horn 1996, Roberts 2006, Beaver \& Clark 2008, Roberts 2011 on English only).

(5) a. [Context: A jaguar and an old donkey got into a fight. The donkey hit the jaguar and then:]

Jaguarete o-ñani tapé-re ha vúrro tuja havẽ avei upe tapé-re.

jaguar A3-run path-on and donkey old moldy too that path-on

'The jaguar ran down a path and the very old donkey, too, ran down that path.'

(Krivoshein de Canese et al. 2005:73)

b. [Context: As children, Maria and her brother once had to cross a field with two bulls in it.]

Ha kyhyje-pó-pe ro-hasa ha che-kyvy aimete ho'a

and scared-hand-in A1PL.EXCL-pass and B1sG-brother almost A3.fall mbokaja ratĩ-'ári.

coco thorn-on

'And we passed fearfully and my brother almost fell into the spines of a coconut plant.'

c. [Context: A monkey looked for a place to stay dry in the rain.]

O-ho oi-ko ha'e yvyra kuá-pe, iñ-akã-ngue-mí-nte

A3-go A3-enter PRON.S.3 tree hole-in B3-head-NOM.TERM-DIM-only o-nohẽ okẽ-me.

A3-come.out door-in

'He entered into the hole of a tree, only his little head was sticking out.'

(Acosta Alcaraz \& Zarratea 2003:23)

Projective contents of possessive and demonstrative noun phrases are also explored in this article. ${ }^{6}$ The example in $6 \mathrm{a}$, repeated from $5 \mathrm{~b}$, features the possessive noun phrase che-kyvy (B1SG-brother) 'my brother', which implies that the speaker has a brother (the POSSESSION implication; a potential uniqueness implication is not examined here). Demonstrative noun phrases are formed with the demonstrative determiners $k o$ 'near the speaker', pe 'near the addressee', or upé/amõ 'away from both the speaker and addressee' (Gregores \& Suárez 1967:141); only the former two, illustrated in 6b and 6c, respectively, are investigated in this article. Three implications of demonstrative noun phrases are explored: that the speaker indicates an entity (the INDICATION implication, for example, that the writer of $6 \mathrm{c}$ indicates the entity referred to with pe jagua 'that $\left.\operatorname{dog}^{\prime}\right),{ }^{7}$ that the indicated entity is salient (the SALIENCE implication), and the implication that the demonstratum has the property denoted by the noun (the DESCRIPTIVE CONTENT

\footnotetext{
${ }^{6}$ Guaraní does not have a definite determiner; determinerless noun phrases like jagua 'dog' can receive definite and indefinite interpretations (Tonhauser \& Colijn 2010).

${ }^{7}$ The speaker's indication fixes the reference of the demonstrative noun phrase. Since calculating the indication is complex and may involve, for example, pointing gestures and other means used by the speaker to direct the addressee's attention, the relevant notion of indication can only be made precise via a theory of context and discourse referents; see, for example, Braun 2012 for discussion.
} 
implication, for example, that the demonstratum of the demonstrative noun phrase in $6 \mathrm{c}$ is a dog); compare Heim's (1982) descriptive content implication.

(6) a. [Context: As children, Maria and her brother once had to cross a field with two bulls in it.]

Ha kyhyje-pó-pe ro-hasa ha che-kyvy aimete ho'a

and scared-hand-in A1PL.EXCL-pass and B1sG-brother almost A3.fall

mbokaja ratĩ-'ári.

coco thorn-on

'And we passed fearfully and my brother almost fell into the spines of a coconut plant.'

b. [Context: A young girl was transformed into a bird.]

Upe pyhare-guive o-je-hecha ko guyra pyahu o-mimbi-pá-va

that night-since A3-JE-see this bird new A3-shine-COMPL-RC jeguá-gui. jewelry-ABL

'Since that night, one has seen this new bird that shines with beauty.'

(Acosta \& de Canese 2003:94)

c. [Context: A cricket is interrupting a man's picnic.]

O-henói hymba jagua peteĩ-me ha pe jagua

A3-call B3.domesticated.animal dog one-at and that dog o-ñepyrũ tuicha o-ñaro.

A3-begin big A3-bark

'He called one of his dogs and that dog began barking loudly.'

The Guaraní subject pronoun $h a$ 'e refers to third-person humans, to the exclusion of animals and inanimate entities: in 7, for example, it refers to the grandmother. The two implications of ha'e explored here are that there is a discourse referent with which the pronoun can be identified (the EXISTENCE implication) and that the referent is human (the HUMAN implication). ${ }^{8}$

(7) [Context: A woman tells that, when she was a child, she lived with her grandmother.]

Ha'e o-pu'ã voi-éterei o-ñami-ha-guã i-vaka.

PRON.S.3 A3-get.up early-very A3-milk-NOM-PURP B3-cow

'She had to get up very early to milk her cows.'

While the above expressions frequently occur in the corpora available to the first author and in her fieldwork notes, expressives, appositives, and nonrestrictive relative clauses (NRRCs) did not, but were easily obtained in elicitation sessions. The implication that the descriptive content holds of the relevant referent was explored for the two expressives given in 8: since both convey a very negative attitude of the speaker toward the referent of the noun phrase in which they occur, both mbóre and aña memby (lit. 'devil child') are translated here with the English expressive bastard (Potts 2005). For appositives and NRRCs, the relevant projective implication is that their content applies to the relevant referent: the appositive in 9a conveys that Maria is one of the speaker's friends, and the NRRC in $9 \mathrm{~b}$, which is marked with the relative clause marker -va'e on the verb, conveys that Maria was born in Germany.

\footnotetext{
${ }^{8}$ Like avei 'too', demonstrative noun phrases and pronouns can be assumed to give rise to salience implications, that is, that the relevant referent is salient. We return to salience implications in $\S 6$.
} 
(8) [Context: Sabina runs into the house, breathlessly, and says:]

a. Pe Márko mbóre o-monda che-kabayu!

that Marko bastard A3-steal B1SG-horse

'That bastard Marko stole my horse!'

b. María o-menda pe aña memby Ríchard-re!

Maria A3-marry that devil child Richard-at

'Maria married that bastard Richard!'

(9) a. María, che-angiru peteĩ, o-vá-ta Paraguaý-pe.

Maria B1SG-friend one A3-move-PRosp Asunción-to

'Maria, one of my friends, is going to move to Asunción.'

b. María, o-nasẽ-va'e-kue Alemánia-pe, oi-ko Brasíl-pe.

Maria A3-born-RC-NOM.TERM Germany-in A3-live Brazil-in

'Maria, who was born in Germany, lives in Brazil.'

The implications of the expressions mentioned above were tested for their behavior with respect to the strong contextual felicity constraint, projection, and obligatory local effect. The relevant diagnostics and the results of their application are discussed in turn in the following three sections, except for salience implications, which are discussed in $\S 6$.

3. Strong contextual felicity. As noted in the introduction, presuppositions are thought of as the paradigm case of projective contents. And presupposition triggers are standardly thought to impose constraints on the context in which they are used. Specifically, it is standardly claimed that utterance of a sentence with presupposition $p$ is felicitous only if $p$ is entailed by the context. When we explore the full range of projective contents, however, it becomes clear that many such contents are not straightforwardly subject to this constraint, including many that are standardly analyzed as presuppositions. Our first diagnostic provides a method for diagnosing the presence of a constraint on context that we call the strong contextual felicity constraint.

We begin with a definition of the property under investigation. Since a particular trigger may contribute more than one projective content (e.g. the third-person pronoun $h a^{\prime} e$ ), but not all such contents need be associated with a strong contextual felicity constraint, the property is formulated as a property of a trigger with respect to a particular implication. The definition in 11 makes reference to $m$-positive contexts, defined in $10 .{ }^{9}$ For the purposes of defining and diagnosing strong contextual felicity (and projection in $\S 4$ ), the relevant context is taken to be the UTTERANCE CONTEXT, the context in which the utterance is made, which is a body of information held in common by the interlocutors in the discourse, including information from the utterance situation, the linguistic context in which the utterance is made, and the information structure of the preceding discourse (e.g. Roberts 2004:197f.). ${ }^{10}$

(10) $m$-POSITIVE AND $m$-NEUTRAL CONTEXTS: An $m$-positive context is an utterance context that entails or implies $m$. An $m$-neutral context is an utterance context that entails or implies neither $m$ nor $\neg m$.

\footnotetext{
${ }^{9}$ As noted in $\S 2$, we characterize projective contents as propositions rather than constraints on context, and the characterization of $m$-positive and $m$-neutral contexts in 10 is congruent with this view (e.g. Stalnaker 1973, 1974, Karttunen 1974, Lewis 1979, Heim 1983). If projective contents associated with a strong contextual felicity constraint were instead characterized as constraints, 10 would define an $m$-positive context as one in which the constraint $m$ is satisfied (see e.g. van der Sandt 1992, Geurts 1999). While we use the previous formulation, our findings could be formulated under either characterization.

${ }^{10}$ Thus, the kind of context we assume is a context in which an utterance can be produced, not an abstract, theoretical construct that is postulated as the context in which an utterance is processed and that may have been enriched with information not present in the utterance context (e.g. Stalnaker 2008, von Fintel 2008).
} 
(11) StRONG CONTEXTUAL FELICITY CONSTRAINT: If utterance of trigger $t$ of projective content $m$ is acceptable only in an $m$-positive context, then $t$ imposes a strong contextual felicity constraint with respect to $m$.

If a trigger of projective content $m$ is acceptable in an $m$-neutral context, this shows that the trigger is not subject to a strong contextual felicity constraint with respect to $m$. This is captured by the subdiagnostic (i) for strong contextual felicity in 12. A judgment of unacceptability in an $m$-neutral context, however, is not sufficient to diagnose the presence of a strong contextual felicity constraint with respect to $m$. To diagnose this, the same utterance should also be tested in a minimally different $m$-positive context, as per subdiagnostic (ii) in 12.

(12) Diagnostic For Strong Contextual felicity: Let $S$ be an atomic sentence that contains trigger $t$ of projective content $m$.

(i) If uttering $S$ is acceptable in an $m$-neutral context, then trigger $t$ does not impose a strong contextual felicity constraint with respect to $m$.

(ii) If uttering $S$ is unacceptable in an $m$-neutral context and acceptable in a minimally different $m$-positive context, then trigger $t$ imposes a strong contextual felicity constraint with respect to $m$.

In the remainder of this section, the application of this diagnostic is illustrated with Guaraní data. These applications demonstrate another, perhaps obvious, methodological issue: in eliciting judgments of acceptability of an utterance in a context, the contexts should be plausible and natural-seeming given the experience of the consultant or experimental participant. The scenarios used in the applications below were invented by the first author to suit the particular fieldwork situation and provide an illustration of the various ways in which the relevant kinds of contexts can be established.

The first set of data we discuss in 13 to 16 involves triggers that are not associated with a strong contextual felicity constraint with respect to the target implication $m$. As per the diagnostic in 12a, we come to this conclusion since the triggers of these contents $m$ are acceptable in $m$-neutral contexts. The example in 13 features the expressive aña memby (devil child) 'bastard'. Like English bastard, using the Guaraní expressive is acceptable in a context where the addressee does not have a low opinion of the referent and did not know prior to the speaker's utterance that the speaker had a low opinion of the referent. The expressive is thus not associated with a strong contextual felicity constraint with respect to the (in this case) negative evaluation.

(13) [Context: Julia and Maria work in a bakery; their boss, who is generally strict but fair, is called Marko. One day, he calls Julia into his office; when she emerges, she says to Maria:]

Pe aña memby Márko ko’ãga oi-pota a-mba'apo iñ-hermáno

that devil child Marko now A3-want A1sG-work B3-brother karnisería-pe.

butcher.shop-in

'That bastard Marko now wants me to work in his brother's butcher shop.'

The next pair of examples shows that appositives and NRRCs in Guaraní, like their English counterparts, are not associated with a strong contextual felicity constraint with respect to the descriptive content implications. ${ }^{11}$ In the examples in 14 , these two types

${ }^{11}$ It is an open, empirical question whether expressives, appositives, and NRRCs in Guaraní have what Potts (2005) calls an antibackgrounding requirement, such that utterances of sentences like (i), where the content of the appositive is already given in the context, are infelicitous 'due to redundancy' (Potts 2005:34).

(i) Simon che-kichiha-kue. Simon, che-kichiha-kue o-ñe'̃ Aleman. Simon B1sG-boyfriend-NOM.TERM Simon B1sG-boyfriend-NOM.TERM A3-speak German 'Simon is my ex-boyfriend. Simon, my ex-boyfriend, speaks German.' 
of expressions are used in $m$-neutral contexts; for example, Raul does not need to already know that Simon is Maria's ex-boyfriend in order for 14 a to be acceptable. ${ }^{12}$

(14) a. [Context: Raul is new in town. His neighbor Simon invites him to his house for a party and introduces him to Maria. When Simon has walked away, Maria tells Raul:]

Simon, che-kichiha-kue, o-ñe'ẽ Aleman.

Simon B1sG-boyfriend-NOM.TERM A3-speak German

'Simon, my ex-boyfriend, speaks German.'

b. [Context: The children in a history class have to give presentations about famous people. Malena has to talk about the pope. She starts with:]

Papa Benedícto 16, o-nasẽ-va'e-kue Alemánia-pe, oi-ko

Pope Benedict 16 A3-born-RC-NOM.TERM Germany-in A3-live

Róma-pe.

Rome-in

'Pope Benedict the 16th, who was born in Germany, lives in Rome.'

We now turn to examples involving aimete 'almost' and -nte 'only'. The example in $15 \mathrm{a}$ shows that the adverb aimete 'almost' is not associated with a strong contextual felicity constraint with respect to the polar implication (here, that Malena did not throw up) since the context is neutral with respect to this implication. The suffix -nte 'only' in $15 \mathrm{~b}$ is likewise felicitously used, although the prejacent implication, that the youngest daughter cleans the house, is not previously known to the mother.

(15) a. [Context: A mother calls for her daughter to come down for dinner. Her daughter doesn't appear so she goes upstairs to check on her. When she comes back down, she says to her husband:]

Maléna hasy ra'e. Aimete o-gue'ẽ.

Malena B3.sick it.seems almost A3-vomit

'It seems that Malena is sick. She almost threw up.'

b. [Context: Carla, a mother of three teenage daughters, falls on the way to the supermarket and breaks her leg. She's been in the hospital for a week when her daughters come to visit her for the first time. When she asks them how they are doing, her youngest daughter blurts out:]

Ché-nte a-mo-potĩ ñande-róga!

PRON.S.1sG-only A1SG-CAUS-clean B1PL.INCL-house

'Only I clean our house!'

The next two examples involve triggers associated with a strong contextual felicity constraint with respect to one implication, but not another. Demonstrative noun phrases, for example, are not associated with a strong contextual felicity constraint with respect to the descriptive content implication $m$ that the demonstratum has the property denoted by the noun, as illustrated in 16a. They are, however, associated with a strong contextual felicity constraint with respect to the indication implication $n$ that the speaker identifies a suitable referent (as is illustrated shortly with 18 below). Likewise, the third-person (human) pronoun $h a^{\prime} e^{\prime}$ in $16 \mathrm{~b}$ is not associated with a strong contextual felicity constraint with respect to the descriptive content implication $m$ that the referent

While all four consultants we worked with on this project recognize the redundancy, utterances like (i) are not generally considered unacceptable. It is thus an open question whether this recognition of redundancy is sufficient for introducing an antibackgrounding requirement for the Guaraní expressions or whether this is an instance of crosslinguistic semantic variation.

${ }^{12}$ In general, $m$-neutral contexts were established in this research by stating neither $m$ nor its negation in the context, rather than explicitly stating that neither $m$ nor its negation is known. The very fact that this methodology distinguishes projective contents along familiar lines confirms its appropriateness. 
is human, but with respect to the existence implication $n$ that there is a discourse referent with which the pronoun can be identified (and this, in turn, is justified in the discussion of 19, below). To diagnose the relevant implications $m$, it is crucial that the context of the examples in 16 is $n$-positive since native-speaker consultants might otherwise reject such utterances because the strong contextual felicity constraint associated with the implications $n$ is not satisfied. Thus, the context of 16 is $n$-positive with respect to the implications $n$ that there is a referent (for $h a^{\prime} e$ ) and that the demonstratum can be identified (for the demonstrative noun phrase).

(16) [Context: You and your friend Maria are walking across a meadow. Both of you can see something ahead, lying in the grass, but you can't identify what it is, even whether it's an object, an animal, or a person. You have much better vision than Maria (who can generally only recognize people when they stand right in front of her). As you approach, you recognize what is lying ahead and tell Maria:]

a. Pe kuimba'e nde-ru.

that man B2sG-father

'That man is your father.'

b. Ha'e peteĩ kuimba'e.

PRON.S.3 one man

'He's a man.'

Since the context of 16 is neutral with respect to the implication that the referent of ha'e is human and the implication that the demonstratum of pe kuimba'e 'that man' is a man, the acceptability of $16 \mathrm{a}$ and $16 \mathrm{~b}$ in this context is evidence that these expressions are not associated with a strong contextual felicity constraint with respect to these implications.

The third set of examples in 17 to 19 illustrates the application of the diagnostic for implications for which the relevant Guaraní triggers are associated with a strong contextual felicity constraint. As mentioned in $\$ 2$, we entertain the hypothesis that avei 'too' conveys an existence implication that there is an alternative, true proposition (see also Heim 1992, van der Sandt \& Geurts 2001, Kripke 2009 for English too). Thus, in $17 \mathrm{a}$, avei 'too' is hypothesized to convey the implication $m$ that somebody besides the bus driver is eating empanadas. The context of $17 \mathrm{a}$ is $m$-neutral since nobody else is known to be eating empanadas (Malena is eating a hamburger). As indicated by the hash mark (\#), the consultants judged this utterance to be unacceptable in this context. ${ }^{13}$

(17) a. [Context: Malena is eating her lunch, a hamburger, on the bus going into town. A woman who she doesn't know sits down next to her and says:] \#Ñande-chofeur o-karu empanáda avei.

A1PL.INCL-driver A3-eat empanada too \#'Our bus driver is eating empanadas, too.'

To conclusively show that the unacceptability of $17 \mathrm{a}$ is due to avei 'too' introducing a strong contextual felicity constraint with respect to $m$, consultants were asked to judge the acceptability of the same utterance in the context given in $17 \mathrm{~b}$, which is $m$-positive since Malena is eating empanadas, not a hamburger. The target utterance in $17 \mathrm{a}$ was judged acceptable by the consultants in the $17 \mathrm{~b}$ context.

${ }^{13}$ The hash marks in the examples in 17 to 19 , and others like them, are based on a variety of verbal means used by the four consultants we worked with on the strong contextual felicity constraint to indicate that they do not accept such examples, including (Spanish variants of ) comments like 'what?!?', 'too is not good here', 'I don't like this', 'why do you say too here?', or 'something is missing', in combination with puzzled facial expressions or shaking of heads. In many cases, consultants also spontaneously offered amendments to the context that rendered the utterances acceptable, such as the first clause of $19 \mathrm{~b}$. 
(17) b. [Context: Same as in 17a, except that Malena is eating empanadas.]

Since $17 \mathrm{a}$ and $17 \mathrm{~b}$ form a minimal pair, we conclude that avei 'too' in $17 \mathrm{a}$ is associated with a strong contextual felicity constraint with respect to $m$.

The example in 18 features the demonstrative noun phrase pe mitã ' $i$ 'that little boy'; we explore the implication $m$ triggered by this noun phrase that the speaker is indicating a suitable referent. As illustrated, the utterance was judged unacceptable in the $m$-neutral context in 18a. The context in $18 \mathrm{~b}$ is $m$-positive: it contains the information that the speaker is showing a relevant picture to the addressees. Since the target utterance in $18 \mathrm{a}$ is acceptable in the context in $18 \mathrm{~b}$, we conclude that demonstrative noun phrases in Guaraní (and English) introduce a strong contextual felicity constraint with respect to the implication that the speaker is indicating a suitable referent.

(18) a. [Context: The children in a sociology class have to give presentations about their families. Marko is up first and he starts with:]

\#Pe mitã-'i che-ryvy.

that child-DIM B1SG-younger.brother

\#'That little boy is my younger brother.'

b. [Context: As in 18a, but now Marko also brings to the presentation a picture of a person that he shows to the class.]

The last example of this set is concerned with the third-person human pronoun $h a^{\prime} e$ and the implication that there is a referent. As illustrated in 19, the utterance with ha' $e$ in $19 \mathrm{a}$ is unacceptable: the context is $m$-neutral since such a referent is not made available in either the context of utterance or Marko's utterance. In contrast, Marko's first utterance in $19 \mathrm{~b}$ introduces such a third person, thus resulting in the second utterance being interpreted in an $m$-positive context. We conclude that $h a^{\prime} e$ is associated with a strong contextual felicity constraint with respect to the implication that there is a referent.

(19) [Context: The children in a sociology class have to give presentations about their families. Marko is up first and he starts with:]
a. \#Ha'e chokokue.
PRON.S.3 farmer
\#'S/he is a farmer.'
b. Che-ru réra Juan. Ha'e chokokue.
B1SG-father name Juan PRON.S.3 farmer
'My father's name is Juan. He is a farmer.'

We turn finally to some results that might seem surprising in light of standard assumptions: we show that the relevant implications of Guaraní possessive noun phrases, change-of-state constructions, and the complement of (oi) kua ' know' are not associated with a strong contextual felicity constraint. As illustrated for these three construction types in 20a, 20b, and 20c, respectively, the four Guaraní consultants we worked with on strong contextual felicity judged these examples (and others like them) acceptable in contexts that are neutral with respect to the relevant implications: the context is neutral in $20 \mathrm{a}$ with respect to the possession implication that the woman has a dog, the context in $20 \mathrm{~b}$ is neutral with respect to the prestate implication that Laura used to do drugs, and $20 \mathrm{c}$ is acceptable even though the addressee cannot be expected to already know the content of the complement clause, that the daughter has to use glasses to drive.

(20) a. [Context: A woman who is being interviewed by a school director for a job as a teacher suddenly interrupts and says:]

A-ha-va'erã a-me'ẽ-ha-guã che-rymba

A1SG-go-MUST A1sG-give-NOM-PURP B1SG-domesticated.animal 
jaguá-pe hembi'u-rã.

dog-at 3.food-NOM.PROSP

'I have to go now to feed my dog.'

b. [Context: Laura, who doesn't live with her parents, visits them and asks them to sit down with her because she has to tell them something:]

Nd-a-je-droga-vé-i-ma.

NEG-A1SG-JE-drug-more-NEG-already

'I've stopped doing drugs.'

c. [Context: A girl backs out of a driveway and hits Susi's car. A woman comes running out of the house, apologizes that her daughter hit Susi's car, and says:]

Ha'e oi-kuaa o-moĩ-va'erã-ha i-lénte o-maneja-ha-guã. PRON.S.3 A3-know A3-put-MUST-NOM 3-glasses A3-drive-NOM-PURP

'She knows that she has to use her glasses to drive.'

Thus, according to the diagnostic in 12, none of these Guaraní expressions are associated with a strong contextual felicity constraint with respect to the relevant implications. Since we judge the English translations of the examples to also be acceptable, as indicated in 20, we conclude that the English expressions are also not associated with a strong contextual felicity constraint with respect to the relevant implications.

Our findings are consistent with the long-standing empirical observation that these types of English expressions can be (and frequently are) used in contexts in which the relevant projective content is not part of the common ground, but constitutes novel information for the addressees (for discussion of so-called INFORMATIVE PRESUPPOSITIONS, see e.g. Karttunen 1974, Stalnaker 1998, 2008, Abbott 2000, 2008, Simons 2001, Spenader 2002, 2003, Gauker 2008, von Fintel 2008).

These empirical observations about English presupposition triggers are traditionally rendered consistent with the assumption that the English expressions impose constraints on contexts (e.g. Heim 1983, van der Sandt 1992, Geurts 1999, Schlenker 2009) by assuming the availability of ACCOMMODATION (Lewis 1979, building on Stalnaker 1974). Accommodation is a process whereby the interpreter 'updates' her view of the context to render it suitable for the utterance of the relevant trigger. From this theoretical perspective, those (English and Guaraní) triggers that test positive on the diagnostic for the strong contextual felicity constraint are subject to a particularly strong constraint on context that cannot be satisfied by accommodation. Those that test negative on the diagnostic might either be subject to a weak constraint that allows for satisfaction via accommodation, or might not be subject to a constraint at all. (See Simons et al. 2011 for arguments against the accommodation view.)

Thus, our findings about English and Guaraní possessive noun phrases, change-ofstate predicates, and factive verbs are not incompatible with current theoretical analyses of such projective content triggers. Crucially, however, the strong contextual felicity diagnostic distinguishes implications that impose constraints on the utterance context from ones that do not; the diagnostic shows that, for example, $20 \mathrm{~b}$ is acceptable in an utterance context that does not include the information that Laura used to do drugs. ${ }^{14}$

In sum, triggers of (projective) contents in both Guaraní and English fall into two groups with respect to the strong contextual felicity constraint: appositives, the adverb aimete 'almost', and the verb (oi)kuaa 'know', among others, are not associated with a

\footnotetext{
${ }^{14}$ Our consultants never gave indication that they were adding assumptions to the context given, such as the implication that the parents must have known that Laura was doing drugs.
} 
strong contextual felicity constraint, while certain implications of triggers like avei 'too', demonstrative noun phrases, and pronouns are. The full set of results is summarized in Table 2 in $§ 7$. That comparable English and Guaraní expressions impose similar constraints contributes to our understanding of crosslinguistic semantic/pragmatic universals and variation. Such a perhaps surprising lack of variation is also observed with regard to projection, the property to which we turn in the next section.

Before turning to projection, however, we want to take the opportunity to compare English, Guaraní, and St'át'imcets. One result of the data presented so far is that both Guaraní and English have different kinds of projective contents, those associated with a strong contextual felicity constraint and those that are not, and that the two languages are remarkably parallel. For St'át'imcets, Matthewson (2006) finds that utterances with $h u 7$ 'more', múta 7 'again/more', tsukw 'stop', and t'it 'also' are acceptable to St'át'imcets speakers in (what we call) $m$-neutral contexts, which suggests that they are not associated with a strong contextual felicity constraint. This means that Guaraní may differ from St'át'imcets, at least with respect to the triggers avei 'too' (Guaraní) and t'it 'also' (St'át'imcets), but perhaps not with respect to the triggers $n(d)(a)$-...-vé-i-ma 'stop' (Guaraní) and tsukw 'stop' (St'át'imcets). Further research is needed to determine whether projective contents across languages are largely similar, or whether the variation between St'át'imcets, on the one hand, and English and Guaraní, on the other, is indicative of wider crosslinguistic semantic variation.

Matthewson arrives at these results by applying the 'Hey, wait a minute!' (HWAM) diagnostic from Shanon 1976, which says that '[u]pon uttering $S$, a speaker $P$ pragmatically presupposes $Q$ if it is suitable for the hearer to utter "One moment, I did not know that $Q$ " in response to S' (p. 248; see also von Fintel 2004). The assumption is that if consultants respond with, for example, 'Hey, wait a minute!', the utterance so responded to has a presupposition failure and, hence, contains a presupposition trigger. From the finding that her St'át'imcets consultants do not respond with HWAM responses, Matthewson concludes that the aforementioned St'át'imcets expressions do not impose a constraint on the common ground.

Whereas both the strong contextual felicity diagnostic and the HWAM diagnostic rely on consultants' acceptability judgments of utterances containing triggers of projective contents, the two diagnostics differ in two crucial aspects, which we believe renders the former diagnostic more straightforward to apply and more empirically reliable. First, the HWAM diagnostic is indirect, since it does not require the fieldworker to elicit an acceptability judgment from the consultant. Instead, the diagnostic assumes that a consultant can (but need not) challenge the utterance that contains the trigger. As a result, a situation in which a consultant does not challenge an utterance that contains a presumed trigger is inconclusive: either the consultant decided not to challenge the contextually unsupported presupposition, or the utterance does not give rise to a contextual constraint. The strong contextual felicity diagnostic circumvents this problem by requiring the fieldworker to elicit acceptability judgments.

A second concern with the HWAM diagnostic is that consultants give HWAM responses to an utterance for a number of reasons besides presupposition failure, for example, to challenge an implicature of the utterance or to indicate some other pragmatic oddity of the utterance (for a similar point, see Matthewson 2006:68 and von Fintel \& Matthewson 2008:184). The strong contextual felicity diagnostic, by contrast, is designed to identify the presence of a particular type of contextual constraint by comparing judgments of utterances containing triggers of implications $m$ in minimally different $m$-neutral and $m$-positive contexts. This diagnostic thus targets more specifically the feature under investigation, namely contextual constraints, than the HWAM diagnostic. 
4. Projection. This section formulates a diagnostic for the projection property, and discusses its application on the basis of Guaraní data. The relevant property, characterized in 21 , refers to the family-of-sentences variants of an atomic sentence $S$, which is defined as a set of sentences consisting of $S$, a negative variant of $S$, an interrogative variant of $S$, an epistemic modal variant of $S$, and a conditional with $S$ as its antecedent (see also 1 above).

(21) Projection: A content $m$ of expression $t$ is projective (i.e. has the property of projection) if and only if $m$ is typically implied by utterances of atomic sentences $S$ containing $t$ and may also be implied by utterances of family-ofsentences variants of $S .{ }^{15}$

Given that projection is the core property we are investigating, it might be expected that we would begin the article with the diagnostic for this property. The reason we do not is that, in order to test a particular implication for projection, one must first determine whether the trigger is subject to a strong contextual felicity constraint with respect to the target implication. Where there is no such constraint, projection of implication $m$ can be diagnosed using implication judgments in $m$-neutral contexts. Where there is such a constraint with respect to $m$, however, this strategy cannot be used to elicit reliable judgments from consultants. Since decontextualized utterances containing triggers associated with a strong contextual felicity constraint are judged to be unacceptable, it is futile to ask a consultant to judge whether, for example, the Guaraní variants of 1a,b with the demonstrative noun phrase ko mburuvicha Fransiagua 'this boss from France' in 22a,b imply that there is a boss from France.

(22) a. \#Ko mburuvicha Fransia-gua oi-ko Lóndre-pe.

this boss France-from A3-live London-in

\#'This boss from France lives in London.'

b. \#Ko mburuvicha Fransia-gua nd-oi-kó-i Lóndre-pe. this boss France-from NEG-A3-live-NEG London-in \#'This boss from France does not live in London.'

We argue that a different strategy must be used with triggers that are associated with a strong contextual felicity constraint. In particular, we propose using a methodology advocated in Matthewson 2004:404, which is to 'test the felicity of sentences like [23a], [23b], and [23c] in a range of discourse contexts, including some which do, and some which do not, contain information corresponding to the presupposition'.

(23) Matthewson 2004:404
a. It is Mary who wants fish.
b. It isn't Mary who wants fish.
c. Is it Mary who wants fish?

The idea of the diagnostic is the following: if utterances of family-of-sentences variants are acceptable in $m$-positive contexts and not acceptable in $m$-neutral ones, one can conclude that the relevant content is projective since the strong contextual felicity constraint it is associated with remains in force even when the trigger of the content is embedded. But this diagnostic is not suitable for diagnosing projection with contents that are not subject to a strong contextual felicity constraint since those are acceptable in $m$-neutral contexts. Thus, it turns out to be necessary to use distinct diagnostics for projection depending on whether a strong contextual felicity constraint is present.

\footnotetext{
${ }^{15}$ The projection property is characterized using the possibility modal may since many projective contents do not obligatorily project; see, for example, Beaver 2001:Ch. 3 for discussion.
} 
The revised family-of-sentences diagnostic for projection that can be applied with linguistically untrained native-speaker consultants is given in 24 . The diagnostic explores the implications of utterances of an atomic sentence $S$ that gives rise to the implication $m$ to be tested for projection, as well as the implications of utterances of other family-of-sentences variants of $S$ (referred to as $F O S(S)$ in 24). Three subdiagnostics are distinguished: subdiagnostic (i), which applies to triggers associated with a strong contextual felicity constraint with respect to the projective content $m$, is the diagnostic from Matthewson 2004, discussed above. Subdiagnostic (ii) applies to triggers not associated with a strong contextual felicity constraint with respect to $m$; like subdiagnostic (iii), it relies on implication judgments.

(24) FAMily-OF-SENTENCES DiAgnostic FOR PROJECTION: Let $S$ be an atomic sentence that gives rise to implication $m$ and $F O S(S)$ be the family-of-sentences variants of $S$.

(i) Trigger $t$ imposes a strong contextual felicity constraint with respect to $m$ : If utterances of $F O S(S)$ are judged unacceptable in an $m$-neutral context and acceptable in an $m$-positive context, then implication $m$ is projective.

(ii) Trigger $t$ does not impose a strong contextual felicity constraint with respect to $m$ : If implication $m$ is implied by utterances of $F O S(S)$ in an $m$-neutral context, then $m$ is projective.

(iii) Trigger $t$ does not impose a strong contextual felicity constraint with respect to $m$, but with respect to some other implication $n$ : If implication $m$ is implied by utterances of $F O S(S)$ in an $m$-neutral and $n$-positive context, then $m$ is projective.

The distinction between subdiagnostics (ii) and (iii) is that the latter is used with triggers associated with a strong contextual felicity constraint not with respect to the implication $m$ being tested but with respect to another implication $n$, which necessitates appropriately controlling the context. In both subdiagnostic (ii) and (iii), it is vital that the context is $m$-neutral so that a judgment that $m$ arises from an utterance can be uncontroversially attributed to the utterance itself.

4.1. The FAMily of SENTENCES IN Guaraní. The Guaraní constructions used in the family-of-sentences diagnostic are illustrated in 25: the simple positive declarative sentence in $25 \mathrm{a}$ is negated in $25 \mathrm{~b}$ and realized as a question in $25 \mathrm{c}$. It occurs as a clausal complement of the possibility modal $i$-katu (B3-possible) 'it's possible' in $25 \mathrm{~d}$ and constitutes the antecedent of a conditional, marked with -ramo 'if', in $25 \mathrm{e}^{16}$

(25) a. Kuehe Cárlos o-jahu. yesterday Carlos A3-bathe

'Carlos bathed yesterday.'

b. Kuehe Cárlos nd-o-jahú-i. yesterday Carlos NEG-A3-bathe-NEG

'Carlos didn't bathe yesterday.'

c. Kuehé-pa Cárlos o-jahu? yesterday-Q Carlos A3-bathe

'Did Carlos bathe yesterday?'

\footnotetext{
${ }^{16}$ Propositional attitude constructions with, for example, 'think', 'say', and 'wonder' have also been successfully applied in Guaraní to diagnose projection, but are omitted here for reasons of space. With such constructions, one must control for the possibility of modal subordination (Roberts 1989, 1995, Heim 1992).
} 

d. I-katu Cárlos o-jahu kuehe.
B3-possible Carlos A3-bathe yesterday
'It's possible that Carlos bathed yesterday.'
e. Kuehe Cárlos o-jahú-ramo, heta o-ké-ta ko ára-pe. yesterday Carlos A3-bathe-if much A3-sleep-ProsP this day-at 'If Carlos bathed yesterday, he is going to sleep a lot today.'

While an utterance of the atomic sentence in 25a commits a Guaraní speaker to the proposition that Carlos bathed yesterday, none of the utterances in 25b-e do, which renders these constructions suitable for the family-of-sentences diagnostic for projection. To motivate this, consider, for example, utterances of $25 \mathrm{a}-\mathrm{e}$ in the context in 26.

(26) [Context: Carlos, an adult, sometimes doesn't bathe for several days in a row. His sister Maria overhears her mother say one of 25a-e to her father.]

The three consultants we worked with on projection were asked whether Maria would think, based on what her mother said, that Carlos bathed yesterday: they responded 'yes' with respect to 25a, 'no' with respect to 25b, and 'I don't know' with respect to $25 \mathrm{c}-\mathrm{e}$. This suggests that $25 \mathrm{~b}-\mathrm{e}$ do not imply that Carlos bathed yesterday, that is, that uttering these complex sentences does not commit the speaker to the content of the atomic sentence embedded in the constructions.

Some additional comments about these constructions are in order. First, sentential negation in Guaraní is realized as a verbal circumfix, as illustrated above, and only expressions inside the circumfix are in the scope of negation (Tonhauser 2009). Since expressions that cannot occur inside the negation circumfix cannot be in the scope of negation, negation is not always a suitable construction for testing projection in Guaraní. The adverb avei 'too', for example, cannot occur inside the negation circumfix, as illustrated in $27 \mathrm{~b}$ (see also n. 17, 19 below).

(27) a.
Cárlos nd-o-jahú-i
avei.
Carlos NEG-A3-bathe-NEG too
'Carlos didn't bathe either.'
b. *Carlós nd-o-jahu-avei-(r)i.

The question in $25 \mathrm{c}$ is not the only possible way to form a question from $25 \mathrm{a}$. A question can also be formed by realizing $25 \mathrm{a}$ with an utterance-final rising intonation and by the variant in 28, where the question marker - pa is realized on Cárlos.

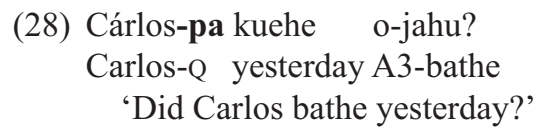

No meaning differences between these question variants have been identified so far. This article therefore assumes that they can all be analyzed as a question operator applying to the meaning of the atomic sentence. But the possibility of the questions differing, for example, in their information-structural contributions and possible effects of this variability on projection should be kept in mind.

In addition to the modal construction illustrated in $25 \mathrm{~d}$, Guaraní also has modal suffixes, including the necessity modal -va'erã in 29a and the possibility modal -ne in $29 \mathrm{~b}$. Since the syntactic relation between these modal suffixes and triggers of projective content is not necessarily apparent from the surface string, this article uses only the modal construction with $i$-katu (B3-possible) 'it's possible' to diagnose projection: as illustrated in $29 \mathrm{c}$, repeated from $25 \mathrm{~d}$, we assume that the modal embeds a clause (marked by square brackets), which may contain a trigger. 
(29) a. [Context: A woman has just heard that a man's daughter has gotten married.]

O-vy'a-íterei-va'erã.

A3-happy-very-MUST

'He must be very happy.'

(theater play, Tonhauser 2011a:210)

b. [Context: A family is discussing who might disrespect them. The father says to the daughter:]

Nde rei-kuáa-ne, che-memby!

PRON.S.2SG A2sG-know-MIGHT B1sG-child

'You might know, my child!'

(theater play, Tonhauser 2011a:210)

c. I-katu [Cárlos o-jahu kuehe].

B3-possible Carlos A3-bathe yesterday

$(=25 \mathrm{~d})$

'It's possible that Carlos bathed yesterday.'

We now diagnose projection in Guaraní.

4.2. Diagnosing projection. Subdiagnostic (i) of the revised family-of-sentences diagnostic for projection in 24 identifies the content $m$ of a trigger $t$ as projective if and only if utterances of $F O S(S)$, where $S$ contains the trigger $t$, are judged unacceptable in an $m$-neutral context and acceptable in an $m$-positive context. Recall that this subdiagnostic is to be used for triggers that have already been determined to be subject to the strong contextual felicity constraint with respect to $m$. The idea is that projection, in these cases, is diagnosed by showing that the strong contextual felicity constraint associated with $m$ remains in force even when the trigger of $m$ is embedded.

The application of the diagnostic to the existence implication of avei 'too' is illustrated in 30 and 31: the atomic utterance in 30a as well as the family-of-sentences variants of $30 \mathrm{a}$ in $30 \mathrm{~b}-\mathrm{d}$ contain avei 'too'. The context in 30 is $m$-neutral since nobody besides the bus driver is (known to be) eating empanadas, while that in 31 is $m$-positive. ${ }^{17}$

(30) [Context: Malena is eating her lunch, a hamburger, on the bus going into town. A woman who she doesn't know sits down next to her and says:]

a. \#Ñande-chofeur o-karu empanáda avei.

A1PL.INCL-driver A3-eat empanada too

\#'Our bus driver is eating empanadas, too.'

b. \#I-katu o-karu empanáda avei ñande-chofeur.

B3-possible A3-eat empanada too A1PL.INCL-driver

\#'It's possible that our bus driver is eating empanadas, too.'

c. \#O-karú-ramo empanáda avei ñande-chofeur, a-sẽ-ta

A3-eat-if empanada too A1PL.INCL-driver A1sG-leave-PROSP kolektívo-gui.

bus-from

\#'If our bus driver is also eating empanadas, I am going to leave the bus.'

\footnotetext{
${ }^{17}$ As discussed in connection with 27 above, avei 'too' cannot be realized inside the negation circumfix. The negative variant of 30a in (i) is acceptable in the context in 30, which is congruent with the hypothesis that avei 'too' here is not in the scope of negation. The variant in (i) is thus not suitable to diagnose whether the implication $m$ of 30 a is projective.
}

(i) [Context as in 30]

Ñande-chofeur nd-o-karú-i empanáda avei.

A1 PL.INCL-driver NEG-A3-eat-NEG empanada too

'Our driver isn't eating empanadas either.' 
d. \#O-karú-pa empanada avei ñande-chofeur?

A3-eat-Q empanada too A1PL.INCL-driver

\#'Is our driver eating empanadas, too?'

(31) [Context: same as in 30, except that Malena is eating empanadas.]

$(=$ context in $17 \mathrm{~b})$

The consultants judged that utterances of the atomic sentence in $30 \mathrm{a}$ as well as utterances of the family-of-sentences variants of $30 \mathrm{a}$ in $30 \mathrm{~b}-\mathrm{d}$ are acceptable in the context of 31 , but not in the context in 30 . We therefore conclude that the family-of-sentences diagnostic for projection identifies the existence implication of avei 'too' as projective.

The examples in 32 explore the projectivity of the existence implication of the pronoun $h a$ 'e (that there is a referent). As indicated, $32 \mathrm{~b}-\mathrm{f}$ are acceptable in the $m$-positive context established by the utterance in 32a. None of 32b-f are acceptable without $32 \mathrm{a}$, that is, in an $m$-neutral context. We therefore conclude that the existence implication is projective. ${ }^{18}$

(32) [Context: Paula is watching a soccer match with Maria, who utters 32a, followed by one of 32b-f.]

a. E-ma'ẽ-mi. Pe arkéro o-joko-kuaa.

A2sG-look-DIM that goalie A3-grab-know

'Look. That goalie knows how to grab the ball.'

b. Ha'e che-kichiha.

PRON.S.3 B1sG-boy/girlfriend

'He's my boyfriend.'

c. Ha'e-pa nde-kichiha?

PRON.S.3-Q B2sG-boy/girlfriend

'Is he your boyfriend?'

d. Ha'e nda-che-kuáa-i chéve.

PRON.S.3 NEG-B1SG-knOW-NEG PRON.O.1SG

'He doesn't know me.'

e. I-katu ha'e o-juga Olímpia-pe ambue arý-pe.

B3-possible PRON.S.3 A3-play Olimpia-at other year-at

'It's possible that he'll play at Olimpia (a famous Paraguayan soccer club) next year.'

f. Ha'e o-porandú-ramo che-número, a-vy’á-ta.

PRON.S.3 A3-ask-if B1sG-number A1sG-happy-PROSP

'If he asks for my number, I am going to be happy.'

Subdiagnostic (ii) of the family-of-sentences diagnostic for projection in 24 identifies a content $m$ as projective if and only if utterances of $F O S(S)$, where $S$ contains the trigger $t$, imply $m$. This subdiagnostic is used for triggers that do NOT impose any strong contextual felicity constraint. The examples in 33 illustrate the application of the diagnostic to an NRRC: the relative clause in 33a implies that Sabina's grandfather has a white beard. The context in 33 is $m$-neutral since it does not entail either that Sabina's grandfather has

\footnotetext{
${ }^{18}$ One of the three consultants we worked with on projection judged family-of-sentences variants of examples like (i) to be acceptable in the context of 32 even without the utterance in 32 a since the pronoun ha'e is compatible with plural as well as singular reference, and can thus refer to the weakly familiar soccer team. Such examples reinforce the need for carefully controlling the context as well as the target utterances, taking into consideration language-particular structures and interpretations.
}

(i) Ha'e Caaguasu-gua. PRON.S.3 Caaguasu-from

'He is/They are from Caaguasu.' 
a white beard or that he does not. To diagnose whether this implication is projective, native-speaker consultants were told that Sabina or her mother says one of 33a-e to Pamela. The consultants were then asked to judge whether these utterances would lead Pamela to want to take pictures of Sabina's grandfather. A '[yes]' after the example indicates that the consultants thought that Pamela would try to take his picture; a '[no]' means that the consultants did not think that Pamela would try to take his picture.

(33) [Context: Pamela is an art student who wants to take black-and-white portraits of old men with white beards. Her friend Sabina says one of $33 \mathrm{a}-\mathrm{d}$ to her; $33 \mathrm{e}$ is uttered by Sabina's mother:]

a. Che-aguélo, hendyva morotĩ-va, oi-ko mombyry. [yes]

B1SG-grandfather B3.beard white-RC A3-live far

'My grandfather, who has a white beard, lives far away.'

b. Che-aguélo, hendyva morotĩ-va, nd-oi-kó-i mombyry. [yes]

B1sG-grandfather B3.beard white-RC NEG-A3-live-NEG far

'My grandfather, who has a white beard, doesn't live far away.'

c. Nd-o-mba'apó-i-rõ ko'ẽro che-aguélo, hendyva morotĩ-va,

NEG-A3-work-NEG-if tomorrow B1SG-grandfather B3.beard white-RC

ja-visitá-ta chupe. [yes]

A1PL.INCL-visit-PROSP PRON.O.3

'If my grandfather, who has a white beard, doesn't work tomorrow, we'll visit him.'

d. I-katu che-aguélo, hendyva morotĩ-va, o-heja re-nohẽ

B3-possible B1sG-grandfather B3.beard white-RC A3-let A2sG-take chupe fóto. [yes] PRON.O.3 foto

'It's possible that my grandfather, who has a white beard, will let you take his picture.'

e. [Sabina's mother, who knows about Pamela's project, comes and asks Sabina:]

E-porandú-ma-pa nde-aguélo, hendyva morotĩ-va-pe? [yes]

A2SG-ask-already-Q B2sG-grandfather B3.beard white-RC-to

'Have you already asked your grandfather, who has a white beard?'

As indicated, the consultants judged each utterance to convey information that would lead Pamela to want to take pictures of Sabina's grandfather. Since Pamela is interested in taking pictures of old men with white beards, we hypothesize that the consultants' responses are due to the content of the NRRC being implied by the examples in 33, thus supporting the hypothesis that this content is projective.

It is important to note that this implication judgment task, when applied to implications that were hypothesized to not be projective, also resulted in the expected responses. With respect to 33a and 33b, for example, consultants were asked whether the grandfather lives close by, which resulted in a positive response for the former and a negative response for the latter. For 33d, when consultants were asked whether Pamela would think that the grandfather would allow her to take his picture, consultants typically responded with (a Spanish variant of) 'I don't know'. These responses, for these examples and others, show that implications hypothesized to be projective and those hypothesized to not be projective are clearly distinguished by this diagnostic.

Further evidence for the suitability of this task and the projectivity of the NRRC is that consultants, when told that Pamela wants to take pictures of old men with RED beards, instead of white ones, consistently responded negatively to the question of 
whether Pamela would want to take a picture of Sabina's grandfather, upon hearing one of $33 \mathrm{a}-\mathrm{e}$.

The examples in 34 below show application of the diagnostic to the prestate implication of the Guaraní change-of-state construction, which is realized using the negation circumfix, as illustrated in 34a. The consultants were asked whether Maria would give the medicine to Marko, given the utterances in 34a-d, with 'yes' and 'no' as possible answers.

(34) [Context: There is a health program that gives medicine to everybody who has ever smoked or currently smokes. Maria is administering the program in a particular town; since she doesn't know the people in the town, she is being assisted by Mario, a local townsman, who tells her 34a-c about Marko; 34d is uttered by another local.]
a. Márko nd-o-pita-vé-i-ma.
[yes]
Marko NEG-A3-smoke-more-NEG-PRF
'Marko doesn't smoke anymore.'
b. I-katu Márko nd-o-pita-vé-i-ma. [yes]
B3-possible Marko NEG-A3-smoke-more-NEG-PRF
'It's possible that Marko doesn't smoke anymore.'
c. Márko nd-o-pita-vé-i-ma-rõ,
Marko NEG-A3-smoke-more-NEG-PRF-if A3-have much money
'If Marko doesn't smoke anymore, he has lots of money.' o-guereko heta pirapire. [yes]
d. [Maria hears another person ask Mario:]
Márko-pa nd-o-pita-vé-i-ma?
Marko-Q NEG-A3-smoke-more-NEG-PRF
'Does Marko not smoke anymore?'

As indicated, the consultants thought that Maria would administer the medicine to Marko as a consequence of each of the utterances in 34a-d. This suggests that each of these utterances implies that Marko used to smoke. We therefore conclude that the prestate implication is projective. When consultants were asked, by contrast, whether Maria would think, based on $34 \mathrm{a}-\mathrm{d}$, that Marko does not smoke anymore, they answered affirmatively for 34a and with (Spanish versions of ) 'I don't know' for 34b-d. These results suggest that the change-of-state implication of 34 a does not project.

The examples in 35 illustrate the application of the diagnostic for projection to the prejacent implication of utterances containing the suffix -nte 'only'. In the given context, the prejacent implication of 35a is the implication that three rings have been stolen. The consultants were asked, given the utterances in 35, how many rings the speaker thought had been taken.

(35) [Context: Clara sells expensive rings. One night, she receives a call from the police telling her that her store has been broken into. At the store, she takes a quick and cursory inventory to tell the police whether something is missing. She says one of $35 \mathrm{a}-\mathrm{c}$ about the thief; $35 \mathrm{~d}$ is uttered by Clara's husband:]

a. Mbohapý-nte o-monda.

three-only A3-steal

'He stole only three.'

b. I-katu mbohapý-nte o-monda.

B3-possible three-only A3-steal

'It's possible that he stole only three.'

c. Mbohapý-nte o-mondá-ramo, a-vy'a.

three-only A3-steal-if A1sG-happy

'If he stole only three, I am happy.' 
d. [Additional context: Clara's husband also arrives at the store and quickly assesses the inventory of remaining rings. He asks Clara:]

O-mondá-pa mbohapý-nte?

A3-steal-Q three-only

'Did he steal only three?'

The three consultants we worked with on projection were asked how many rings they thought had been stolen, given the utterances in 35 . The consultants consistently judged that $35 \mathrm{a}$ conveys that three rings (and not more) were stolen, and that 35b-d convey that at least three rings (and possibly more) were stolen. These responses suggest that the prejacent implication arises from each of $35 \mathrm{a}-\mathrm{d} .{ }^{19}$ We therefore conclude that the prejacent implication of -nte 'only' is projective.

While the three consultants' responses for 35 uniformly support the hypothesis that the prejacent implication of an utterance with -nte 'only' is projective, this was not the case for all examples used to test the projection of the prejacent of -nte 'only' and the polar implication of aimete 'almost'. While one consultant consistently gave responses on a variety of examples that support the hypothesis that these two implications are projective, the other two consultants gave responses to several examples containing these triggers that did not support the hypothesis (in particular when the trigger was embedded under a modal or occurred in the antecedent of a conditional). Thus, while there is evidence that the prejacent of -nte 'only' and the polar implication of aimete 'almost' are projective in Guaraní, we note that their projective behavior may be less robust than that of implications of other triggers (where the three consultants' judgments strongly agreed with each other). Evidence for a similar kind of language-internal variation in English is that not all English-speaking semanticists agree that the prejacent of only is projective (e.g. Horn 2002). Furthermore, Amaral and colleagues (2011) observe in an experiment with linguistically untrained English speakers that the prejacent of only is particularly easy to refute compared to other projective contents. Language-internal variation among projective contents triggered by English and German expressions has also been observed in Spenader 2002, 2003, Smith \& Hall 2011, and Xue \& Onea 2011.

Subdiagnostic (iii) applies when diagnosing implications $m$ of triggers not associated with a strong contextual felicity constraint with respect to $m$ but with respect to another implication $n$. The difference from subdiagnostic (ii) is that the context constructed for the target utterances must entail the content of the implication $n$, to prevent infelicity due to failure of a strong contextual felicity constraint. The application of the diagnostic is illustrated with the examples in 36 , which contain the demonstrative noun phrase ko mbo'ehára 'this teacher'. As discussed in §3, demonstrative noun phrases are associated with a strong contextual felicity constraint with respect to the implication $n$ that the speaker indicates a referent, but not with respect to the property-attribution implication $m$, here the implication that the referent is a teacher. The context of 36 is thus constructed such that a referent is indicated (namely by the cousin) and such that the cousin, but not the consultant, knows that the property 'teacher' is true of the referent (the property-attribution implication $m$ ). To diagnose whether the implication $m$ is projective, the native-speaker consultants were asked what they would think Clara's job is upon hearing the cousin's utterances in 36a-e.

\footnotetext{
${ }^{19}$ By similar logic to that discussed in $\mathrm{n} .17$, the negative variant of $35 \mathrm{a}$ given in (i) is not suitable to diagnose projection.
}

(i) Mbohapý-nte nd-o-mondá-i. three-only NEG-A3-steal-NEG 'Only three were not stolen.' 
(36) [Context: You are visiting your cousin in Luque. One day, the two of you are taking a stroll across town. You come across a woman that you don't know. Your cousin introduces her as Clara and says one of 36a to 36e to you:]

a. Ko mbo'ehára o-japo heta mba'e porã ñande-puéblo-re. [teacher] this teacher A3-do many thing good B1PL.INCL-town-for

'This teacher has done many good things for our town.' 20

b. Mavavéa nd-o-hekombo'e-kuáa-i mitã-nguéra-pe ko nobody NEG-A3-discipline-know-NEG child-PL-at this mbo'ehára-gui. [teacher] teacher-ABL

'Nobody knows better how to discipline children than this teacher.'

c. I-katu ko mbo'ehára intendénte-rã. [teacher] B3-possible this teacher mayor-NOM.PROSP

'It's possible that this teacher is the future mayor.'

d. Che-memby o-ñe'ẽ-rõ ndéve ko mbo'ehára-gui, he'í-ta B1sG-child A3-talk-if PRON.O.2SG this teacher-ABL A3.say-PROSP mba'e porã-nte chugui. [teacher] thing good-only PRON.O.3.ABL

'If my daughter talks to you about this teacher, she'll only say good things about her.'

e. E-sena-se ko mbo'ehára-ndi? [teacher]

A2sG-dine-DES this teacher-with

'Do you want to have dinner with this teacher?'

The annotation '[teacher]' after the examples indicates that the consultants thought that Clara was a teacher, given that particular utterance. This is evidence that the implication that the demonstratum has the property denoted by the noun is projective.

4.3. Summary AND Discussion. This section has shown that the contents explored in $\S 3$ are indeed projective contents. Crucially, we presented evidence that Guaraní has expressions that give rise to projective contents, thus providing the first systematic evidence of projection in a non-European language. The set of contents identified as projective is summarized in Table 2 in $\S 7$.

The crucial insight behind the diagnostic for projection is that different subdiagnostics are needed for triggers that are associated with a strong contextual felicity constraint with respect to the relevant implication and those that are not. The diagnostic developed for the former case relies on judgments of acceptability; that for the latter case depends on implication judgments. A slightly revised statement of the diagnostic is given in 37, where the subdiagnostics (ii) and (iii) of the version in 24 are combined as subdiagnostic (ii), which imposes the additional requirement that the context be appropriately controlled for, as illustrated above.

(37) FAMILY-OF-SENTENCES DiAgNostic FOR PROJECTION (REVISED): Let $S$ be an atomic sentence that gives rise to implication $m$. Let $F O S(S)$ be a set of sentences consisting of $S$, a negative variant of $S$, an interrogative variant of $S$, a modal variant of $S$, and a conditional with $S$ as its antecedent.

\footnotetext{
${ }^{20}$ This example also provides evidence that a demonstrative noun phrase with $k o$ is not associated with a strong contextual felicity constraint with respect to the property-attribution implication.
} 
(i) Trigger $t$ imposes a strong contextual felicity constraint with respect to $m$ : If utterances of $F O S(S)$ are judged unacceptable in an $m$-neutral context and acceptable in an $m$-positive context, then implication $m$ is projective.

(ii) Trigger $t$ does not impose a strong contextual felicity constraint with respect to $m$ : If implication $m$ is implied by utterances of $F O S(S)$ in a context that is $m$-neutral and appropriately controls for any strong contextual felicity constraints introduced by the trigger, then $m$ is projective.

The literature on projection and projective contents has mostly relied on data from the limited set of languages with native-speaker semanticists. It is our hope that this diagnostic for projection leads to data from a wider variety of languages and a more general population of speakers informing this literature.

An important difference between the present study and previous studies of projective content in many languages, including English, concerns the evidence provided for projection. Levinson and Annamalai (1992), for example, list only Tamil sentences alongside their claimed presuppositions (see also von Fintel \& Matthewson 2008:182 for this point), and Matthewson (2006) argues that the St'át'imcets expressions $h u 7$ 'more', múta7 'again/more', tsukw 'stop', and t'it 'also' are presupposition triggers, but does not provide evidence for projection. In contrast, the previous section has provided detailed empirical evidence for the relevant contents being projective. This evidence consists of (i) the relevant contextualized utterances that form part of the diagnostic, (ii) the questions posed to the consultants, (iii) the consultants' responses, and (iv) our reasoning for taking these responses to support the hypothesis that the relevant contents are projective. It is vital to provide such evidence, even when working with one's intuitions, since such evidence constitutes the empirical support for a claim about projectivity. Furthermore, diagnostics can be revised and improved on only if given in full detail. Finally, the results obtained through particular diagnostics are replicable (in the same language) or comparable to results in other languages only if all of the relevant pieces of evidence are provided.

The finding that Guaraní translations of English triggers of projective content are also triggers of projective content is new. Whether the finding is surprising depends on one's assumptions about the way in which projection arises. One position is that natural language expressions conventionally encode (i.e. as part of their lexical entries) which aspects of their content are projective (e.g. Karttunen \& Peters 1979). On this view, we might expect to find crosslinguistic differences in whether, for example, the polar implication of an expression like almost and its translation in other languages is projective or not. The finding that comparable Guaraní and English expressions so consistently show projection of the same elements of content is perhaps surprising on this view. An alternative position is that projection is derived from a combination of lexical meaning and some set of general principles of interpretation (for specific proposals along these lines, see e.g. Levinson 1983 and Simons 2001). On this view, one might not expect to find crosslinguistic differences in the projective properties of expressions that are otherwise similar as regards their meaning and function. The finding from English and Guaraní could be taken to present some support for this view.

5. OBligatory LOCAL EFFECT. The properties of projection and strong contextual felicity distinguish two classes of projective content in English and Guaraní. In this section, we explore another property of projective contents: the property obligatory local effect, which distinguishes projective contents according to their behavior with respect 
to embedding operators like propositional attitude verbs, modals, and conditionals; see also, for example, Gazdar 1979, Zeevat 2000, and Potts 2005 for discussions of the variability of projective contents with respect to this property.

Because this property is perhaps not very familiar, we begin by illustrating it with some cases from English. The embedding operators considered here are contributed by propositional attitude verbs such as believe and think. An utterance of a sentence containing such a belief-predicate attributes to the attitude holder the belief that the proposition denoted by the embedded clause is true, that is, part of the attitude holder's epistemic state. For example, an utterance of the sentence Jane believes that Bill is a rock star attributes to Jane the belief that Bill is a rock star (while remaining neutral as to whether Bill actually is a rock star). In the examples considered in this section, belief-predicates embed clauses that contain projective content triggers. We are interested in the interaction between the belief-predicate and the projective content of the embedded clause. Consider the examples in 38 .

(38) a. Jane believes that Bill has stopped smoking (although he's actually never been a smoker).

b. Joan is crazy. She's hallucinating that some geniuses in Silicon Valley have invented a new brain chip that's been installed in her left temporal lobe and permits her to speak any of a number of languages she's never studied. Joan believes that her chip, which she had installed last month, has a twelve year guarantee.

(Amaral et al. 2007:735f., boldface added)

The projective contents of the embedded clauses are, in 38a, the prestate implication of stop that Bill has been a smoker, and, in 38b, the implication of the NRRC that Joan's chip was installed last month. The example in 38a attributes to Jane the belief that Bill has stopped smoking, which necessarily also attributes to her the belief that Bill has been a smoker in the past. Example 38b attributes to Joan the belief that her chip has a twelve month guarantee, and also that it was installed last month. Since the projective contents of stop smoking and the NRRC are part of the attitude holders' belief states in these two examples, we say that these projective contents of stop and the NRRC have local effect here.

We can also construct examples where the content of an NRRC does not have a local effect: example $39 \mathrm{~b}$ is one such case. In contrast, there are no cases where the projective content of stop fails to have local effect. Example 39a contrasts with $39 \mathrm{~b}$.

(39) a. \#Jane believes that Bill has stopped smoking and that he has never been a smoker.

b. Jane believes that Bill, who is Sue's cousin, is Sue's brother.

Example 39a is unacceptable since the conjoined clauses embedded under the beliefpredicate attribute inconsistent beliefs to Jane: the first conjunct necessarily implies that Jane believes that Bill has been a smoker, which is contradicted by the second conjunct. The fact that the projective contents of change-of-state predicates that occur embedded under a belief-predicate always have local effect is what we refer to as obligatory local effect.

The projective content of an NRRC, by contrast, may but need not have local effect, as illustrated with the example in $39 \mathrm{~b}$. Here, the content of the NRRC is not understood to be part of the belief attribution: the speaker of $39 \mathrm{~b}$ does not attribute to Jane the belief that Bill is Sue's cousin, but only the belief that Bill is Sue's brother; that is, the utterance does not attribute contradictory beliefs to Jane. Thus, whereas the projective 
content of NRRCs may have local effect (as in 38b), it does not have obligatory local effect.

We define the obligatory local effect property for belief-predicates in 40 .

(40) Obligatory local efFect: A projective content $m$ with trigger $t$ has obligatory local effect if and only if, when $t$ is syntactically embedded in the complement of a belief-predicate $B, m$ necessarily is part of the content that is targeted by, and within the scope of, $B$.

A diagnostic for obligatory local effect using belief-predicates is given in $41 .{ }^{21}$ Like the diagnostic for projection, it has three parts: subdiagnostic (i) applies to triggers $t$ associated with a strong contextual felicity constraint with respect to $m$; subdiagnostics (ii) and (iii) apply to trigger/content pairs where the trigger is not associated with a strong contextual felicity constraint with respect to $m$, though alternatively (ii) and (iii) could have been combined, as discussed for projection above. In the three subdiagnostics, it is assumed that $S_{I}$ is an atomic sentence with trigger $t$ of content $m$ and $S$ is a sentence where $S_{I}$ is embedded under a belief-predicate. We offer three possible implementations for subdiagnostics (ii) and (iii) for reasons to be discussed in $\S \S 5.1$ and 5.2.

(41) Diagnostic for obligatory local efFect using Belief-Predicates: Let $S_{1}$ be an atomic sentence with trigger $t$ of content $m$.

(i) Trigger $t$ imposes a strong contextual felicity constraint with respect to $m$ : Let $S$ be a sentence where $S_{l}$ is embedded under a belief-predicate. If utterance of $S$ is acceptable when the utterance context entails $m$ but the bearer of the attitude is explicitly ignorant of $m$, then the content $m$ with trigger $t$ need not have its effect locally, that is, does not have obligatory local effect.

(ii) Trigger $t$ does not impose a strong contextual felicity constraint: Three possible implementations:

a. Let $S_{2}$ be an atomic sentence that implies $\neg m$, and $S$ a sentence where both $S_{1}$ and $S_{2}$ are conjoined under the same belief-predicate. If utterance of $S$ is acceptable, then the content $m$ with trigger $t$ need not have its effect locally, that is, does not have obligatory local effect.

b. Let $S_{2}$ be an atomic sentence that implies $\neg m$. Embed $S_{1}$ under a belief-predicate with attitude holder $A$ to form the complex sentence $S_{1}^{\prime}$ and embed $S_{2}$ under the same belief-predicate with the same attitude holder $A$ to form the complex sentence $S_{2}^{\prime}$. Let $S$ be a conjunction of $S_{1}^{\prime}$ and $S_{2}^{\prime}$. If utterance of $S$ is acceptable, then the content $m$ with trigger $t$ need not have its effect locally, that is, does not have obligatory local effect.

c. Let $S_{2}$ be an atomic sentence that contains both trigger $t$ of content $m$ and also implies $\neg m$. Let $S$ be a sentence where $S_{2}$ is embedded under a belief-predicate. If utterance of $S$ is acceptable, then the con-

\footnotetext{
${ }^{21}$ For a belief-predicate $B$ to be suitable for the obligatory local effect diagnostic, it must have the following two properties (Dan Velleman, p.c.): (i) $B$ is consistency-enforcing, which means that if an epistemic agent $a$ stands in the $B$-relation to propositions $p$ and $q$, then $p$ and $q$ must be consistent, and (ii) $B$ is nonveridical, which means that if an epistemic agent stands in the $B$-relation to proposition $p, p$ is not entailed to be true (or false). The examples in 45 show that the Guaraní predicate (oi)mo 'a 'think' that is used to diagnose obligatory local effect in Guaraní has these properties.
} 
tent $m$ with trigger $t$ need not have its effect locally, that is, does not have obligatory local effect.

(iii) Trigger $t$ does not impose a strong contextual felicity constraint with respect to $m$, but with respect to another implication $n$ : This subdiagnostic has the same three possible implementations as subdiagnostic (ii), with the addition that the context in which $S$ is uttered entails that the speaker and the bearer of the attitude know $n$.

Recall from $\S 3$ that triggers associated with a strong contextual felicity constraint require the content $m$ to be part of the relevant context PRIOR TO UTTERANCE. For an utterance of a sentence $S$ in which such a trigger occurs in a clause embedded under a beliefpredicate, the relevant context could in principle be the global (utterance) context, or the epistemic state of the bearer of the attitude. That epistemic state is the local context of interpretation for the complement of the belief-predicate. ${ }^{22}$ With such triggers, subdiagnostic (i) diagnoses obligatory local effect by setting up a situation in which $m$ is part of the global (utterance) context, but in which the bearer of the attitude is explicitly ignorant of $m$; that is, $m$ is not part of the local context. If utterance of $S$ is acceptable in this situation, we assume that this is because the strong contextual felicity constraint associated with $m$ may be satisfied nonlocally, that is, by the global (utterance) context. In this case, the content $m$ with trigger $t$ does not have obligatory local effect.

If, by contrast, an utterance of $S$ is NOT acceptable in this situation, we assume that this may indicate that the strong contextual felicity constraint associated with $m$ must be satisfied in the local context (the attitude holder's epistemic state). In this case, the content $m$ with trigger $t$ may have obligatory local effect. Before drawing the conclusion that content $m$ with trigger $t$ has obligatory local effect, it is vital to test more than one example. (See for example the discussion of appositives in n. 25.)

With triggers not associated with a strong contextual felicity constraint with respect to content $m$ (subdiagnostics (ii) and (iii)), the diagnostics for obligatory local effect are based on the general assumption that the epistemic state of a (rational) bearer of an attitude cannot contain both the content $m$ contributed by the trigger $t$ as well as the negation of the content, that is, $\neg m$. With such triggers, obligatory local effect is diagnosed by setting up a situation where the epistemic state of the bearer of the attitude contains $\neg m$. If utterance of $S$ is acceptable in this situation, we assume that this is because $m$ does not have to become part of the attitude holder's epistemic state, but may merely become part of the global context; that is, the content $m$ with trigger $t$ does not have obligatory local effect. In this case, only $\neg m$ is part of the epistemic state of the bearer of the attitude. If, by contrast, an utterance of $S$ is unacceptable in this situation, we assume that this is because trigger $t$ requires the content $m$ to be part of the content that is targeted by the belief-predicate, that is, to be part of the epistemic state of the bearer of the attitude: utterance of $S$ is unacceptable since the epistemic state of the bearer of the attitude contains both $m$ and $\neg m$. Again, testing more than one example before concluding that content $m$ with trigger $t$ has obligatory local effect is vital. ${ }^{23}$

\footnotetext{
${ }^{22}$ Heim (1983) introduces the notion of local context in her account of presupposition projection, but does not give a general definition of a local context, a set of worlds. What we might call the local context for the content of the complement clause of belief-predicates is complexly determined, as a function of the global context plus the modal accessibility relation determined by the semantics of the belief-predicate itself, plus the denotation of its subject, the bearer of the attitude.

${ }^{23}$ We note here that our diagnostics for obligatory local effect (as well as for projection) use a surface-level notion of locality. As a result, interpretation of the diagnostics is potentially complicated by the fact that an absence of obligatory local effect could result from different sources. For example, in a framework involving
} 
5.1. THE SYNTAX AND SEMANTICS OF THE GUARANí BELIEF-PREDICATE (oi)mo ' $\tilde{a}$ 'THINK'. The Guaraní examples used to diagnose obligatory local effect feature the beliefpredicate (oi)mo' $\tilde{a}$ 'think', illustrated in 42: the epistemic agent is referred to by the preverbal proper name Juan; the clausal complement of the belief-predicate is $i$-sy hasy 'his mother is sick', which is obligatorily marked with the nominalizing suffix - $h a$ on the predicate.

(42) Juan oi-mo'ã i-sy hasy-ha.

Juan A3-think B3-mother B3.sick-NOM

'Juan thinks that his mother is sick.'

Implementation (a) of subdiagnostics (ii) and (iii) of the diagnostic for obligatory local effect in 41 calls for sentences in which a conjoined clause is the complement of a belief-predicate. In the example in 43, the clausal complements are conjoined with $h a$ 'and'. Evidence that both clauses are complements of the belief-predicate is that the predicates of both clauses are marked with the nominalizing suffix $-h a$, which does not occur on matrix clause predicates.

(43) Juan oi-mo’ã [[i-sy hasy-ha] ha [i-túva i-kaigue-ha]]

Juan A3-think B3-mother B3.sick-NOM and B3-father B3-sluggish-NOM

'Juan thinks that his mother is sick and that his father is sluggish.'

Two of the three consultants we worked with on obligatory local effect considered some constructions like 43 not entirely acceptable, rendering implementation (a) of subdiagnostics (ii) and (iii) inapplicable. Such consultants preferred minimal variants where the belief-predicate was repeated, as in the variant of 43 in 44 . We remain agnostic here about whether 44 involves conjunction of sentences (with no independent noun phrase realizing the subject of the second conjunct) or conjunction of verb phrases. What is important for implementation (b) of subdiagnostics (ii) and (iii) is that both complements are understood as being interpreted with respect to Juan's epistemic state.

(44) Juan oi-mo'ã [i-sy hasy-ha] ha oi-mo'ã (avei) [i-túva Juan A3-think B3-mother B3.sick-NOM and A3-think too B3-father i-kaigue-ha] B3-sluggish-NOM

'Juan thinks that his mother is sick and he (also) thinks that his father is sluggish.'

That propositional attitude constructions with (oi)mo' $\tilde{a}$ 'think' create a local context distinct from the global utterance context is illustrated with the example in 45a. This example is not contradictory since the global context, in which Juan's mother is not sick, is distinct from the local context created by the belief-predicate, in which Juan's mother is sick. The example in $45 \mathrm{~b}$ shows that an epistemic agent cannot stand in the (oi)mo' $\tilde{a}$ 'think'-relation to contradictory propositions.

(45) [Context: The speaker has just visited Juan's mother and knows that she is healthy.]
a. Juan oi-mo'ã i-sy
hasy-ha há=katu na-'añeté-i.
Juan A3-think B3-mother B3.sick-NOM and=CONTR NEG-true-NEG
'Juan thinks that his mother is sick but that's not true.'

\footnotetext{
a level of logical form (LF) distinct from surface form, perhaps mediated by syntactic movement, there would be a nonsurface notion of locality (i.e. locality at LF). In such frameworks, it would be important to know where the trigger was interpreted at LF before drawing strong conclusions about the nature of the projective implications associated with the trigger.
} 
b. \#Juan oi-mo'ã i-sy hasy-ha ha oi-mo'ã avei i-sy

Juan A3-think B3-mother B3.sick-NOM and A3-think also B3-mother nda-hasy-i-ha.

NEG-B3.sick-NEG-NOM

\#'Juan thinks that his mother is sick and he also thinks that she is not sick.'

We now diagnose obligatory local effect in Guaraní.

5.2. Diagnosing obligatory local EFFeCt. Subdiagnostic (i) of the obligatory local effect diagnostic in 41 is used for triggers $t$ of contents $m$ associated with a strong contextual felicity constraint. Consider a sentence $S$ whose main verb is a belief-predicate whose complement clause contains the trigger $t$ of $m$. If uttering $S$ is always unacceptable when the global context entails $m$ but the bearer of the attitude is explicitly ignorant of $m$ (i.e. the local context is $m$-neutral), then subdiagnostic (i) identifies $m$ as having obligatory local effect. In 46 , we apply this diagnostic to the existence implications of the triggers avei 'too' and the pronoun ha'e.

(46) a. \#Raul o-va Buénos Áires-pe, há=katu Juan nd-oi-kuáa-i.

Raul A3-move Buenos Aires-to and=CONTR Juan NEG-A3-know-NEG

Ha'e oi-mo'ã Maléna avei o-va-ha Buénos Áires-pe. PRON.S.3 A3-think Malena too A3-move-NOM Buenos Aires-to

\#'Raul moved to Buenos Aires, but Juan doesn't know that. He thinks that Malena, too, moved to Buenos Aires.'

b. [Context: The speaker, Ricardo, and Malena are lost in a city they've never visited before. The speaker, who, together with Ricardo, is a bit ahead of Malena, says:]

\#E-ma'ẽ-mi! Upépe o-ĩ peteĩ kuimba'e. Maléna nd-o-hechá-i.

A2sG-look-DIM there A3-be one man Malena NEG-A3-see-NEG

Ha'e oi-mo'ã ha'e hasy-ha.

PRON.S.3 A3-think PRON.S.3 B3.sick-NOM

\#'Look! There's a man. Malena doesn't see him. She thinks he is sick.'

In 46a, avei 'too' triggers the implication that there is a true proposition $m$ of the form ' $x$ moved to Buenos Aires'. In this discourse, the only salient proposition of this form is the proposition that Raul moved to Buenos Aires. The global context of 46a is $m$-positive since Raul is known to have moved to Buenos Aires, and the relevant local context is $m$-neutral since the attitude holder Juan is not aware that Raul moved to Buenos Aires. The respective global and local contexts in $46 \mathrm{~b}$ are $m$-positive and $m$-neutral, too: while the existence of the man is given in the global context, Malena is explicitly ignorant of it. We conclude from the unacceptability of these examples and others like them that these implications of these triggers necessarily have their effect locally, that is, have obligatory local effect. ${ }^{24}$

Subdiagnostic (ii) is used to diagnose triggers $t$ of content $m$ not associated with a strong contextual felicity constraint. In the examples in 47 , the second implementation of the subdiagnostic is used to explore the polar implication of aimete 'almost' and the

\footnotetext{
${ }^{24}$ One of the three consultants we worked with on obligatory local effect considered $46 \mathrm{~b}$ acceptable. This consultant commented that Malena does not need to see the man to think of him that he is sick. This comment suggests that this consultant took the existence of the discourse referent for $h a$ ' $e$ to be entailed in Malena's epistemic state; that is, the local context was not $m$-neutral for this consultant. His comment also indicates that the referent is not salient for Malena. Examples not presented here suggest that the salience implication of $h a$ 'e does not have obligatory local effect, which is in line with other observations on salience implications in $\S 6$.
} 
prejacent of -nte 'only'. In 47a, for example, the clause embedded under the beliefpredicate (oi)mo' $\tilde{a}$ 'think' in the first conjunct contains the trigger aimete 'almost', which implies (here) that Malena did not break her leg $(m)$. The clause embedded under the second conjunct implies that Malena broke her leg $(\neg m)$. Since the examples and others like them are unacceptable, we conclude that these contents have obligatory local effect with respect to the relevant triggers.

(47) [Context: Juan is a doctor at the scene of an accident. His friend says about him:]

a. \#Juan oi-mo'ã Maléna aimete o-pe-ha hetyma ha oi-mo'ã

Juan A3-think Malena almost A3-break-NOM B3.leg and B3-think avei Maléna o-pe-ha hetyma.

also Malena A3-break-NOM B3.leg

\#'Juan thinks that Malena almost broke her leg and that Malena broke her leg.'

b. \#Juan oi-mo'ã Maléna-nte o-pe-ha hetyma ha oi-mo'ã avei

Juan A3-think Malena-only A3-break-NOM B3.leg and A3-think too

Maléna nd-o-pe-i-ha hetyma.

Malena NEG-A3-break-NEG-NOM B3.leg

\#'Juan thinks that only Malena broke her leg and that Malena didn't break her leg.'

Examples like 48 were used to show that the content of the complement of (oi)kuaa 'know' has obligatory local effect.

(48) \#Ángel oi-mo’ã i-túva oi-kuaa-ha iñ-ermána o-guereko kichiha Angel A3-think B3-father A3-know-NOM B3-sister A3-have boyfriend ha Ángel oi-mo'ã avei iñ-ermána nd-o-guerekó-i-ha kichiha. and Angel A3-think too B3-sister NEG-A3-have-NEG-NOM boyfriend

\#'Angel thinks that his father knows that his sister has a boyfriend and Angel also thinks that his sister doesn't have a boyfriend.'

In 49, the diagnostic for obligatory local effect is applied to an appositive that implies that Angela Merkel is Germany's chancellor $(m)$, while the remainder of the clause implies its negation (by way of implying that Angela Merkel is the president of Argentina). Implementation (c) of subdiagnostic (ii) is used here.

(49) [Context: Sabine is from Germany and knows the politicians there very well. Angela Merkel, the chancellor of Germany, is currently visiting farmers in Paraguay, among them Juan. Sabine says: $]^{25}$

Juan oi-mo’ã Angéla Mérkel, Alemánia mburuvicha, ha'e-ha

Juan A3-think Angela Merkel Germany boss PRON.S.3-NOM

Argentína mburuvicha.

Argentina boss

'Juan thinks that Angela Merkel, the German chancellor, is the Argentinian president.'

\footnotetext{
${ }^{25}$ The context of this example strongly reinforces that Sabine is an expert on German politics while Juan is not. This ensures that the content of the appositive cannot plausibly be part of the epistemic state of the attitude holder. Some utterances where the context was not constrained this way were judged unacceptable by the consultants, suggesting that the content of the appositive can be part of the local context, the attitude holder's epistemic state. Whether there is indeed a difference in the extent to which appositives (and NRRCs) have obligatory local effect in English and Guaraní is a question for future research (for a relevant discussion of English appositives and expressives, see Harris \& Potts 2009).
} 
Since the resulting utterance (and others like it) is acceptable in Guaraní, we conclude that appositives in this language (like their English counterparts) do not need to have their effect locally, that is, do not have obligatory local effect. The same is true for Guaraní expressives; see also Potts 2007 and references therein for the observation that expressives do not necessarily contribute to the local context.

Subdiagnostic (iii) of the obligatory local effect diagnostic in 41 differs from subdiagnostic (ii) in the way the context is controlled. We illustrate the application of this subdiagnostic with the third-person pronoun $h a^{\prime} e$ with respect to the human implication in 50a. Since the pronoun is associated with a strong contextual felicity constraint with respect to the existence implication, the global context in which the utterance that contains the (boldfaced) pronoun is interpreted entails the existence of a discourse referent with which the pronoun can be identified, as does the local context (Malena's epistemic state). Crucially, the entity is inanimate in the local context since Malena thinks it is a stone sculpture.

(50) a. [Context: The speaker, Ricardo, and Malena are lost and looking for somebody to ask for directions. The speaker, who is walking ahead with Ricardo, says:]

E-ma’ẽ-mi! Upépe o-ĩ peteĩ kuimba'e, há=katu Maléna

A2sG-look-DIM there A3-be one man and $=$ CONTR Malena nd-oi-kuáa-i. Ha'e oi-mo'ã ha'e-ha peteĩ ta'anga NEG-A3-know-NEG PRON.S.3 A3-think PRON.S.3-NOM one figure ita-guí-gua. stone-of-from

'Look! There's a man over there, but Malena doesn't know that (it's a man). She thinks he is a stone sculpture.'

The fact that the consultants judge this (and utterances like it) acceptable is evidence that the implication of $h a^{\prime} e$ that its referent is human does not need to have its effect locally, that is, does not have obligatory local effect. Additional support for this conclusion is the unacceptability of example $50 \mathrm{~b}$, where the complement clause of $50 \mathrm{a}$ is realized as a matrix clause: $50 \mathrm{a}$ would be unacceptable if the human implication had to be interpreted locally. ${ }^{26}$

(50) b. [Context: The speaker is standing in front of a stone sculpture.]

\#Ha'e peteĩ ta'anga ita-guí-gua. PRON.S.3 one figure stone-of-from

(Intended: 'It's a stone sculpture.')

The example in 51 shows that the content of the possessive relation contributed by possessive noun phrases need not be part of the local context, that is, does not have obligatory local effect: Brian does not know that the dog is Carmen's and, in fact, need not know this to think that it is fierce. ${ }^{27}$

${ }^{26}$ The utterance in (i) with the nonattributive demonstrative pronoun kóva would be used in this context.

(i) Kóva peteĩ ta'anga ita-guí-gua.

this one figure stone-of-from 'This is a stone sculpture.'

${ }^{27}$ We note that consultants rejected examples like 51 when the context did not support a de re interpretation of the possessive noun phrase. We leave an investigation of the relation between obligatory local effect and the de re/de dicto interpretation of noun phrases to future research. 
(51) [Context: Brian and Pedro are strolling down the street. They see a dog chasing a cat. Brian comments to Pedro that the dog looks fierce. Pedro knows that the dog is Carmen's, but Brian doesn't know that. Pedro later says to his wife:]

Brian oi-mo'ã Carmen jagua i-ñaro-ha.

Brian A3-think Carmen dog B3-fierce-NOM

'Brian thinks that Carmen's dog is fierce.'

Example 52 illustrates an application of the obligatory local effect diagnostic to the implication of demonstrative noun phrases that the demonstratum has the property denoted by the noun. (We note that one of the three consultants we worked with on such examples did not consistently accept them.) This example also shows that indication implications of demonstrative noun phrases do not have obligatory local effect: Malena does not need to think that the speaker of 52 is indicating something (namely Raul). Example 53 is another example that shows that the indication implication does not have obligatory local effect: Sabina does not need to think that the speaker of 53 is indicating something.

(52) [Context: The speaker and her addressee are at a reception, with Raul standing at the next table. Malena is not present.]

Raul mburuvicha há=katu Maléna nd-oi-kuáa-i. Ha'e oi-mo’ã

Raul boss and=CONTR Malena NEG-A3-know-NEG PRON.S.3 A3-think ko mburuvicha pa'i-ha.

this boss priest-NOM

'Raul is a (company) boss, but Malena doesn't know that. She thinks this boss is a priest.'

(53) [Context: Marko and Maria are walking down the street together when Marko points at a house; their school friend Sabina is not with them.]

Sabína oi-mo'ã ai-ko-ha pe óga-pe.

Sabina A3-think A1sG-live-NOM that house-in

'Sabina thinks that I live in that house.'

5.3. SUMMARY. In sum, projective contents differ in whether they are necessarily part of the local context of a belief-predicate, the attitude holder's epistemic state: the existence implication of the pronoun $h a$ 'e and the polar implication of aimete 'almost', for example, have obligatory local effect, while the descriptive content of appositives and the human implication of the pronoun $h a$ 'e do not. The full results of applying the diagnostics for obligatory local effect are summarized in Table 2 in $\$ 7$.

6. Class D PROJECTIVE CONTENTS. In the previous three sections, the properties strong contextual felicity, projection, and obligatory local effect were discussed for a wide variety of implications. Almost all of the discussed implications are in classes A, B, or C, where class $\mathrm{A}$ contents are associated with a strong contextual felicity constraint and have obligatory local effect, class B projective contents are not associated with a strong contextual felicity constraint and do not have obligatory local effect, and class $\mathrm{C}$ projective contents are not associated with a strong contextual felicity constraint but have obligatory local effect (cf. $\S 1$ ). We have also identified one implication in class D, that is, an implication that is associated with a strong contextual felicity requirement, but that does not have obligatory local effect, namely the indication implication of Guaraní demonstrative noun phrases. This section explores class D contents, including salience implications, in English and Guaraní. 
The data in 54a-c illustrate that the requirement associated with English indexical expressions like that car - that something is being indicated by the speaker-exhibits the same properties. The infelicity of 54a shows that there is a strong contextual felicity requirement to the effect that the speaker is indicating something. The infelicity of $54 \mathrm{~b}$ shows that this requirement survives embedding from the antecedent of a conditional, and hence is projective. The consistency of 54c shows that the implication that the speaker is indicating something does not have an obligatory local effect.

(54) a. [Context: Barney and Fred are walking down the street. They haven't been discussing cars. Barney does not point to or otherwise indicate any of the cars parked in the street. Barney says:]

\#Wilma likes that car.

b. [Same context as in 54a:]

\#If Wilma likes that car, she has good taste.

c. [Context: Barney points at a car and says:]

Pebbles thinks Wilma likes that car, but of course Pebbles has no idea that I'm pointing to it.

Are there other such projective contents for which there is a strong contextual felicity requirement, but no obligatory local effect? As we argue here, the answer is very clearly yes, but the issue is complicated by the fact that the implications in question are often hard to state straightforwardly, and hard to disentangle from other implications that may fall into different classes. Specifically, the class D implications that we now discuss tend to concern not facts about the external world that the interlocutors seek to describe, but facts about the discourse situation itself. It is for this reason that class D implications, at least the ones we have examined, are particularly demanding to study in a fieldwork situation. Therefore from an empirical point of view, and although we present some preliminary results from the field, the reader might reasonably take the current section not as pinning down robust and reliable methods for studying class D implications, but rather as presenting what is to us a quite tantalizing new area of research, an area in which we hope we will inspire future study.

Let us start with the observation that the additive particle too must be associated with something more than a merely existential presupposition (see Green 1968, Kripke 2009). Kripke (2009) notes that in examples like 55, the putative existential presupposition that someone other than Sam is having dinner in New York is surely satisfied, and that even so the example would be highly marked in a situation where the interlocutors had not explicitly exchanged information about some other individual having dinner in New York.

(55) Sam is having dinner in New York tonight, too.

(Kripke 2009:373)

We take the oddity of 55, uttered out of the blue, and the comparable Guaraní example 17 a discussed in $\S 3$, to show that these triggers are associated with a strong contextual felicity requirement. Given that the existential claim that someone other than Sam is having dinner in New York can reasonably be taken to be in the common ground of the interlocutors, the strong contextual felicity requirement must be of a different nature: we suggest (adapting from Kripke and others) that it is the constraint that there is a SALIENT established proposition to the effect that someone (other than Sam) is having dinner in New York. Furthermore, it is easily shown that this is a projective implication, though we omit presentation of the arguments here. We are more interested in the question of whether the salience implication has obligatory local effect. 
Consider 56. Here the strong contextual felicity requirement on salience is satisfied. In this example, 55 is embedded under the attitude verb think. Crucially, the context makes clear that the bearer of the attitude, Jane, is not aware of the utterance of the sentence containing too. Clearly there is no implication that Jane thinks that a certain proposition-for example, the proposition that Mary is having dinner in New York-is salient in the utterance context, since Jane does not know anything about the utterance context, and need not have any particular beliefs about what is salient in the minds of the interlocutors. It follows that the salience implication does not have obligatory local effect, and thence that this implication is a class D projective content.

(56) Mary's having dinner in New York tonight, and Jane thinks Sam is having dinner in New York tonight, too. Coincidence? I don't think so! But don't let Jane know that I told you about Mary or Sam's dinner plans, or she'll say I'm being a gossip.

Just as for English additives, Guaraní avei ‘too' has at least some projective implications that lack an obligatory local effect. In example 57, the additive is embedded under an attitude. Consider the implication that there is a salient true proposition concerning someone other than Carlos, and saying of that individual that they are drunk. This is satisfied contextually by the prior claim that Claudia is drunk. But a hearer will not infer that Brian thinks that this proposition is salient, or indeed that Brian has any particular knowledge of the conversation between Susi and Maria or knowledge of what is salient for them.

(57) [Context: Susi, Brian, Carlos, and Maria are at a party with lots of drunk people. Susi is worried about her friend Claudia and says to Maria:]

Cláudia o-ka'u ha Brian oi-mo’ã Cárlos avei o-ka'u-ha. Claudia A3-drunk and Brian A3-think Carlos too A3-drunk-NOM

'Claudia is drunk and Brian thinks that Carlos, too, is drunk.'

We note here that although it is clear that additive particles have at least some implications that lack obligatory local effect, it remains controversial exactly which implications associated with additives have an obligatory local effect. Consider this much-discussed example due to Heim.

(58) [Context: Two kids are talking to each other on the phone.] (Heim 1992:209) John: $\mathrm{I}_{1}$ am already in bed.

Mary: My parents think $\mathrm{I}_{\mathrm{F}}$ am also $_{\mathbf{1}}$ in bed.

Heim's claim is that Mary's utterance does not imply that her parents believe that John (or any other specific individual other than Mary) is in bed. We get mixed judgments on whether Mary's utterance in 58 is acceptable, but judgments are much sharper with respect to Mary's utterances in 59a and 59b, both of which are strikingly unacceptable.

(59) [Context: Two kids are talking to each other on the phone.]

a. John: $\mathrm{I}_{1}$ am already in bed.

Mary: \#My parents think $\mathrm{I}_{\mathrm{F}}$ am also ${ }_{1}$ in bed but that you aren't.

b. John: $\mathrm{I}_{1}$ am wearing the PJs that you left behind last time we had a sleepover.

Mary: \#My parents think $\mathrm{I}_{\mathrm{F}}$ am also ${ }_{1}$ wearing those PJs.

Our judgments on 59a and 59b are in agreement with the Guaraní data in 46a above, implying that additives are associated with at least some implication that has an obligatory local effect, and suggesting that this implication must be at least as strong as an ex- 
istential. A position consistent with the data we have collected is that, in addition to their class D salience implication, additives are associated with a class A projective implication that includes both existence of another individual satisfying the relevant predication, and the possibility that the actual antecedent in the discourse is true. Thus in 58, Mary's utterance would require (i) that Mary's parents thought someone else was in bed, and (ii) that Mary's parents thought it possible that John was in bed. While consistent with the data, such a position is ad hoc, and we leave open for future research a fuller listing of the projective implications associated with additives, and a thorough study of how those implications can be separated cleanly from each other for empirical study and classification. ${ }^{28}$

Another candidate for a class D projective implication may be a more generalized version of the implications associated with additives, namely the implication resulting from focus to the effect that alternatives are salient. Thus, if Wilma in example 60 carries a nuclear pitch accent, 60 is felicitous if the sentence follows an earlier question 'Who called Fred?', but not if it follows 'Who did Wilma call?', to which it is not CONGRUENT.

(60) WiLma called Fred.

We suggest that the implication that alternatives are salient is a strong candidate for class D implication. First, the oddity of 60 out of the blue suggests that there is a strong contextual felicity constraint. Second, it is clear that this implication projects, since 61a, in which a clause with a focused constituent is embedded in the antecedent of a conditional, places similar requirements as regards the salience of alternatives of the form ' $\mathrm{X}$ called Fred', as does 60. Third, in 61b there is no implication from Barney's utterance to the effect that Pebbles thinks it is salient (to Betty and Barney) who called Fred, or even that Pebbles is aware of other alternatives.

(61) a. If WiLma called Fred, that would explain a lot.

b. Betty: I'm wondering who called Fred.

Barney: Pebbles thinks that WiLma called him.

While we leave detailed exploration of these subtle discourse-oriented implications for future work, we nonetheless tentatively include them in Table 2 in the next section, which summarizes our findings about projective contents in English and Guaraní.

7. Projective CONTENT IN ENGLiSh AND PaRAguayan GUARANí. The results of applying the diagnostics for strong contextual felicity, projection, and obligatory local effect are summarized in Table 2 for pairs of English (E) and Guaraní (G) triggers and contents. The third column identifies the various contents as projective; the fourth and fifth columns identify whether a trigger/content pair has the strong contextual felicity or obligatory local effect properties (yes) or not (no). The final column identifies the four classes of projective content that empirically emerge from the application of the diagnostics.

We hypothesize that the projection, strong contextual felicity, and obligatory local effect properties delineate theoretically cohesive classes of projective contents in the two languages. The projective contents summarized in Table 2 fall into four classes: triggers of projective contents in both classes $\mathrm{A}$ and $\mathrm{D}$ impose a strong contextual felicity constraint with respect to the relevant content, but while the contents in class A have obligatory local effect, those in class D do not. The contents in classes B and D are not

\footnotetext{
${ }^{28}$ According van der Sandt and Geurts's (2001) proposal, the two implications contributed by too are in classes B and D, but see Beaver \& Zeevat 2007 for problems with that proposal.
} 


\begin{tabular}{|c|c|c|c|c|c|}
\hline & & \multicolumn{3}{|c|}{ PROPERTIES OF CONTENTS } & \multirow[b]{4}{*}{ CLASS } \\
\hline & & & STRONG & OBLIGATORY & \\
\hline & & & CONTEXTUAL & LOCAL & \\
\hline & & PROJECTION & FELICITY & EFFECT & \\
\hline LANGUAGE & TRIGGER/CONTENT & & & & \multirow{5}{*}{$\mathbf{A}$} \\
\hline \multirow[t]{2}{*}{$\mathrm{E}$} & Pronoun/existence of referent & yes & yes & yes & \\
\hline & too/existence of alternative & yes & yes & yes & \\
\hline \multirow[t]{2}{*}{ G } & $h a^{\prime} e^{\prime}$ ' $3 \mathrm{rd}$ '/existence of referent & yes & yes & yes & \\
\hline & avei 'too'/existence of alternative & yes & yes & yes & \\
\hline \multirow[t]{5}{*}{$\mathrm{E}$} & Expressive & yes & no & no & \multirow[t]{11}{*}{ B } \\
\hline & Appositive & yes & no & no & \\
\hline & NRRC & yes & no & no & \\
\hline & that $\mathrm{N} /$ property attribution & yes & no & no & \\
\hline & Possessive NP/possessive relation & yes & no & no & \\
\hline \multirow[t]{6}{*}{ G } & Expressive & yes & no & no & \\
\hline & Appositive & yes & no & no & \\
\hline & NRRC & yes & no & no & \\
\hline & Possessive NP/possessive relation & yes & no & no & \\
\hline & $h a^{\prime} e$ '3rd'/human referent & yes & no & no & \\
\hline & Demonstrative NP/property attribution & yes & no & no & \\
\hline \multirow[t]{4}{*}{$\mathrm{E}$} & almost/polar implication & yes & no & yes & \multirow[t]{8}{*}{$\mathbf{C}$} \\
\hline & know/content of complement & yes & no & yes & \\
\hline & only/prejacent implication & yes & no & yes & \\
\hline & stop/prestate holds & yes & no & yes & \\
\hline \multirow[t]{4}{*}{ G } & aimete 'almost'/polar implication & yes & no & yes & \\
\hline & (oi)kuaa 'know'/content of complement & yes & no & yes & \\
\hline & -nte 'only'/prejacent implication & yes & no & yes & \\
\hline & $\begin{array}{l}n(d)(a)-\ldots-v e \text { - }-i-m a \text { 'not anymore'/prestate } \\
\quad \text { holds }\end{array}$ & yes & no & yes & \\
\hline \multirow[t]{3}{*}{$\mathrm{E}$} & too/salience of established alternative & yes & yes & no & \multirow[t]{5}{*}{$\mathbf{D}$} \\
\hline & Focus/salience of alternatives & yes & yes & no & \\
\hline & that $\mathrm{N} /$ speaker indicates suitable entity & yes & yes & no & \\
\hline \multirow[t]{2}{*}{ G } & avei 'too'/salience of established alternative & yes & yes & no & \\
\hline & $\begin{array}{l}\text { Demonstrative NP/speaker indicates suitable } \\
\text { entity }\end{array}$ & yes & yes & no & \\
\hline
\end{tabular}

TABLE 2. Properties of some projective contents in English and Paraguayan Guaraní.

associated with a strong contextual felicity constraint, but while the contents in class B do not have an obligatory local effect, those in class $\mathrm{C}$ do.

The classes of projective content that empirically emerge from the application of diagnostics for strong contextual felicity and obligatory local effect align with theoretically identifiable classes of projective contents. The strong contextual felicity constraint can be taken to reflect an anaphoric requirement imposed by a trigger on the context; thus, triggers of projective contents in our classes A and D are expressions typically called anaphoric, including pronouns, demonstrative noun phrases, and the adverb too (and its Guaraní counterpart). The contents in class B subsume Potts's CONVENTIONAL IMPLICATURES, but also include some of the projective contents contributed by pronouns, possessive noun phrases, and demonstrative noun phrases. Our research shows that a particular lexical item can give rise to several projective implications with distinct status: for example, in the case of the third-person pronoun $h a^{\prime} e$, we have evidence that it gives rise to both a class A and a class B projective content. In addition, the discussion of salience in $\S 6$ suggests that pronouns might also be associated with class D implications. With anaphoric triggers, the descriptive content implication thus need not be anaphoric. The 
set of projective implications in class $\mathrm{C}$ are perhaps the most heterogeneous of the classes, and we anticipate further subdivisions by considering additional properties of projective contents. Classical presuppositions, such as those triggered by stop and know (and their Guaraní counterparts), are contained in this class, but also the prejacent of only (and Guaraní -nte), which is not clearly presuppositional in the classical sense (see e.g. Horn 1996, Roberts 2006, 2011, Beaver \& Clark 2008 for discussion).

Table 2 allows for a comparison between English and Guaraní that reveals many parallels between projective contents in the two languages. The four subclasses of projective contents are populated by expressions from the two languages and, more importantly, there is significant overlap in the properties of the projective contents of comparable expressions: for example, the content of expressives is projective in both languages, is not associated with a strong contextual felicity constraint, and does not have obligatory local effect. Likewise, the prejacent implications of Guaraní -nte 'only' and English only are projective in the two languages, not associated with a strong contextual felicity constraint, but must have their effect locally. The only differences conclusively established so far pertain to variation in the inventory of triggers of projective contents. For example, English, but not Guaraní, has definite noun phrases, which trigger anaphoric projective implications (e.g. Roberts 2003). English third-person pronouns like she and he give rise to gender implications, while the Guaraní third-person pronoun ha'e only requires its referent(s) to be human.

8. IMPLICATIONS FOR THEORIES OF PROJECTION. In the introduction to this article, we observed that projection has largely been treated as a property of presuppositions, and has primarily been explored from this perspective. The evidence we have presented confirms that projection does not, in fact, pick out the traditional class of presuppositions in English or Guaraní. In fact, none of the four classes of projective content identified above encompasses all of the contents traditionally considered presuppositions. The evidence presented suggests minimally that the classes of projective content A, B, $\mathrm{C}$, and $\mathrm{D}$ form a subtaxonomy in a better-developed taxonomy of meaning and are distinct on some dimension from, for example, ordinary entailments.

The observation that projective content is heterogeneous (see also e.g. Chierchia \& McConnell-Ginet 1990, Simons 2001, Abusch 2002, 2010, Potts 2005, 2007, Abbott 2006) has important implications for theories of projection. We argue that a principled theory of projection that accounts for all classes of projective content should, if attainable, be preferable to a collection of disparate theories that individually account only for subsets of projection phenomena. Consider, for example, accounts of projection based on the assumption that presuppositions place constraints on the context: on these accounts, presupposition projection occurs when this constraint is required (for one reason or another) to be satisfied outside of the local context in which the trigger occurs (Karttunen 1974, Heim 1983, van der Sandt 1992, Geurts 1999). Since only projective implications in classes A and D are associated with a strong contextual felicity constraint, these accounts of projection cannot easily generalize to implications in classes B and $\mathrm{C}$ that are not associated with such a constraint.

A similar objection can be raised against even more recent models, like that of Schlenker (2009), where it is assumed that a presupposition is satisfied in its local context if it is entailed by it. Since, in general, the relevant local context is the context set ('which encodes what the speech act participants take for granted'; Schlenker 2009:2), presuppositions are predicted to project. The heterogeneity of projective content, in particular the finding that many such contents are not associated with a strong contextual 
felicity constraint, provides an argument against an inclusive analysis of projection based on local satisfaction.

In theories like those of Karttunen and Peters (1979) and Potts (2005, 2007), projective content is not targeted by entailment-canceling operators because projective content is handled in a separate dimension from ordinary content and is thus not accessible to such operators (see also Jayez 2009 for a related account). But whether a particular content is projective depends on context (Simons et al. 2011), a fact that is not captured by analyses that assume that projective content is conventionally specified as such.

Schlenker (2007) proposes to capture the projectivity of expressive contents, one of the types of content considered by Potts (2005), by arguing that such contents are 'informative self-fulfilling presuppositions'. Expanding on Stalnaker 2002, the assumption is that since the speaker presents herself as presupposing that $p$, the other speech act participants update their beliefs to take into account the speaker's belief, thus guaranteeing that $p$ is common belief and projective. As noted in Schlenker 2007:243, this process crucially relies on the relevant content being 'indexical and attitudinal, and thus predicat[ing] something of the speaker's mental states'. Given that not all projective contents exhibit these properties, Schlenker's proposal does not account for the projectivity of the entire class of projective content.

We return, then, to the position proposed in the introduction to this article: a fully adequate account of projection must be based on a detailed understanding of the empirical behavior of projective contents. This article constitutes a contribution to that understanding.

In sum, we have proposed a preliminary taxonomy of projective content on the basis of a detailed exploration of a wide range of projective contents in English and Guaraní. Projection is a property common to all contents considered here, whereas strong contextual felicity and obligatory local effect point to the heterogeneity of the set of projective contents. The application of the diagnostics for these properties has shown that Guaraní has expressions that give rise to projective contents and that comparable expressions in English and Guaraní exhibit striking parallels with respect to the kind of projective content they convey. The current taxonomy already has strong implications for the taxonomy of meaning and theories of projection, implying classifications that cross-cut the traditional notion of presupposition. We expect (and hope) that future research on projective contents in other languages on the basis of the diagnostics developed here will lead to further refinements of the taxonomy we have proposed.

\section{REFERENCES}

Abbott, Barbara. 2000. Presuppositions as non-assertions. Journal of Pragmatics 32. $1419-37$.

Aвbott, BARBARA. 2006. Where have some of the presuppositions gone? Drawing the boundaries of meaning: Neo-Gricean studies in pragmatics and semantics in honor of Laurence R. Horn, ed. by Betty J. Birner and Gregory Ward, 1-20. Philadelphia: John Benjamins.

Aвbott, Barbara. 2008. Presuppositions and common ground. Linguistics and Philosophy $31.523-38$.

ABUSCH, DoRIT. 2002. Lexical alternatives as a source of pragmatic presupposition. Proceedings of Semantics and Linguistic Theory (SALT) 13.1-19.

ABusch, DORIT. 2010. Presupposition triggering from alternatives. Journal of Semantics 27. $37-80$.

Acosta, Feliciano, and Natalia Krivoshein de Canese (eds.) 2003. Mombe'ugua'u: Colleción de mitos, fábulas y leyendas paraguayas. Asunción: Servilibro. 
Acosta Alcaraz, Feliciano, and Tadeo Zarratea (eds.) 2003. Ka'i rembiasakue (Las aventuras de ca'i). Spanish translations by Natalia Krivoshein de Canese. Asunción: Servilibro.

Adelaar, Willem F. H. 1994. The nasal/oral distinction in Paraguayan Guaraní suffixes. Revista Latinoamericana de Estudios Etnolingüísticos 8.125-33.

Amaral, Patrícia Matos; Chris Cummins; and Napoleon Katsos. 2011. Experimental evidence on the distinction between foregrounded and backgrounded meaning. Proceedings of the 2011 ESSLLI Workshop on Projective Content, 1-7.

Amaral, Patrícia Matos; Craige Roberts; and E. Allyn Smith. 2007. Review of Potts 2005. Linguistics and Philosophy 30.707-49.

Beaver, David. 2001. Presupposition and assertion in dynamic semantics. Stanford, CA: CSLI Publications.

Beaver, David, and Brady Clark. 2008. Sense and sensitivity: How focus determines meaning. Oxford: Wiley-Blackwell.

Beaver, DaVID, and HenK ZeEvat. 2007. Accommodation. The Oxford handbook of linguistic interfaces, ed. by Gillian Ramchand and Charles Reiss, 533-38. Oxford: Oxford University Press.

BRAUn, DAVID. 2012. Indexicals. The Stanford encyclopedia of philosophy (summer 2012 edn.), ed. by Edward N. Zalta. Online: http://plato.stanford.edu/archives/sum2012 /entries/indexicals/.

Chemla, Emmanuel. 2009. Presuppositions of quantified sentences: Experimental data. Natural Language Semantics 17.299-340.

Chierchia, Gennaro, and Sally McConnell-Ginet. 1990. Meaning and grammar. Cambridge, MA: MIT Press.

Clopper, Cynthia G., and Judith Tonhauser. 2011. On the prosodic coding of focus in Paraguayan Guaraní. West Coast Conference on Formal Linguistics (WCCFL) 28.24957.

Clopper, Cynthia G., and Judith Tonhauser. 2013. The prosody of focus in Paraguayan Guaraní. International Journal of American Linguistics, to appear.

Dessaint, Michel. 1996. Mba'éixapa he'i ara avañe'ẽme (comment dit-on le temps en guarani?). Modèles linguistiques 33.17.9-17.

GAUKer, Christopher. 2008. Against accommodation: Heim, van der Sandt and the presupposition projection problem. Philosophical Perspectives: Philosophy of Language 22. $129-63$.

GazDar, Gerald. 1979. Pragmatics: Implicature, presuppositions, and logical form. New York: Academic Press.

GEURTS, BART. 1999. Presuppositions and pronouns. Oxford: Elsevier.

Geurts, Bart; Napoleon Katsos; Chris Cummins; Jonas Moons; and Leo Noordman. 2010. Scalar quantifiers: Logic, acquisition, and processing. Language and Cognitive Processes 25.130-48.

Green, Georgia. 1968. On 'too' and 'either', and just on 'too' and 'either', either. Chicago Linguistic Society 4.22-39.

Gregores, Emma, and Jorge A. SuÁrez. 1967. A description of colloquial Guaraní. The Hague: Mouton.

Grice, H. Paul. 1975. Logic and conversation. Syntax and semantics, vol. 3: Speech acts, ed. by Peter Cole and Jerry L. Morgan, 64-75. New York: Academic Press.

HARris, Jesse A., and Christopher POTTS. 2009. Perspective-shifting with appositives and expressives. Linguistics and Philosophy 32.523-52.

HeIM, IRENE. 1982. The semantics of definite and indefinite noun phrases. Amherst: University of Massachusetts, Amherst dissertation.

HeIM, IRENE. 1983. On the projection problem for presuppositions. West Coast Conference on Formal Linguistics (WCCFL) 2.114-25.

HeIm, IRENE. 1992. Presupposition projection and the semantics of attitude verbs. Journal of Semantics 9.183-221.

Horn, LAWRENCE R. 1996. Exclusive company: Only and the dynamics of vertical inference. Journal of Semantics 13.1-40.

Horn, Laurence R. 2002. Assertoric inertia and NPI licencing. Chicago Linguistic Society (Parasession on negation and polarity) 38.2.55-82.

JAYEZ, JACQUES. 2009. Projective meaning and attachment. Proceedings of the 17th Amsterdam Colloquium, 306-15. 
Karttunen, Lauri. 1974. Presupposition and linguistic context. Theoretical Linguistics $1.181-93$.

Karttunen, Lauri, and Stanley Peters. 1979. Conventional implicature. Syntax and semantics, vol. 11: Presuppositions, ed. by Choon-Kyu Oh and David A. Dinneen, 1-56. New York: Academic Press.

KRIPKE, SAUl A. 2009. Presupposition and anaphora: Remarks on the formulation of the projection problem. Linguistic Inquiry 40.367-86.

Krivoshein de Canese, Natalia; Carlos Martinez Gamba; and Feliciano Acosta AlCARAZ (eds.) 2005. Tetãgua remimombe'u: Cuentos populares paraguayos. Asunción: Servilibro.

Langendoen, D. Terence, and Harris Savin. 1971. The projection problem for presuppositions. Studies in linguistic semantics, ed. by Charles J. Fillmore and D. Terence Langendoen, 54-60. New York: Holt, Rinehart and Winston.

Levinson, Stephen C. 1983. Pragmatics. Cambridge: Cambridge University Press.

LeVinson, StePhen C., and E. AnNAMALAi. 1992. Why presuppositions aren't conventional. Language and text: Studies in honour of Ashok R. Kelkar, ed. by R. N. Srivastava, 227-42. Delhi: Kalinga.

LEWIS, DAVID. 1979. Scorekeeping in a language game. Semantics from different points of view, ed. by Rainer Bäuerle, Urs Egli, and Arnim von Stechow, 172-87. Berlin: Springer.

Liuzzi, SiLvio. 1987. Temps et aspect en Guaraní. Paris: Université de Paris-Sorbonne.

Liuzzi, Silvio, and Pablo KirTchuK. 1989. Tiempo y aspecto en Guaraní. Amerindia 14.942.

Lunt, Horace G. 1973. Remarks on nasality: The case of Guaraní. A festschrift for Morris Halle, ed. by Stephen R. Anderson and Paul Kiparsky, 131-39. New York: Holt, Rinehart and Winston.

MatTHEWSOn, Lisa. 1998. Determiner systems and quantificational strategies: Evidence from Salish. The Hague: Holland Academic Graphics. [Based on 1996 University of British Columbia dissertation.]

MatTHEwSOn, Lisa. 2004. On the methodology of semantic fieldwork. International Journal of American Linguistics 70.4.369-415.

MatThewson, Lisa. 2006. Presupposition and cross-linguistic variation. North East Linguistic Society (NELS) 26.63-76.

MatTHEWSON, LisA. 2008. Pronouns, presuppositions, and semantic variation. Proceedings of Semantics and Linguistic Theory (SALT) 18.527-50.

MinisTERIO DE EDUCACIÓN Y CULTURA. 2004. La educación bilingüe en la reforma educativa Paraguaya. Online: http://www.arandurape.edu.py/pdf/la_reforma_y_la_educacion bilingue.pdf.

NorDHoff, Sebastian. 2004. Nomen/Verb-Distinktion im Guaraní. Cologne: University of Cologne master's thesis.

POTTS, ChristoPHeR. 2005. The logic of conventional implicatures. Oxford: Oxford University Press.

PotTs, Christopher. 2007. The expressive dimension. Theoretical Linguistics 33.165-97.

Rivas, Alberto M. 1974. Nasalization in Guaraní. North East Linguistic Society (NELS) 5.134-43.

RoBerTS, CRAige. 1989. Modal subordination and pronominal anaphora in discourse. Linguistics and Philosophy 12.689-721.

RoberTS, Craige. 1995. Domain restriction in dynamic semantics. Quantification in natural languages, ed. by Emmon Bach, Eloise Jelinek, Angelika Kratzer, and Barbara H. Partee, 661-700. Dordrecht: Kluwer.

Roberts, Craige. 2003. Uniqueness in definite noun phrases. Linguistics and Philosophy 26.3.287-350.

Roberts, Craige. 2004. Context in dynamic interpretation. The handbook of pragmatics, ed. by Laurence R. Horn and Gregory Ward, 97-220. Oxford: Blackwell.

Roberts, Craige. 2006. Only, presupposition and implicature. Columbus: The Ohio State University, MS.

RoberTS, Craige. 2011. Only: A case study in projective meaning. The Baltic International Yearbook of Cognition, Logic and Communication 6. Online: http://thebalticyearbook .org/journals/baltic/article/view/1581.

SCHLENKER, PhILIPPE. 2007. Expressive presuppositions. Theoretical Linguistics 33.237-45.

SCHLENKER, PHILIPPE. 2009. Local contexts. Semantics and Pragmatics 2.1-78. 
SCHWARZ, Florian. 2007. Processing presupposed content. Journal of Semantics 24.373416.

Shain, Cory, and Judith Tonhauser. 2010. The synchrony and diachrony of differential object marking in Paraguayan Guaraní. Language Variation and Change 22.321-46.

SHANON, BENNY. 1976. On the two kinds of presuppositions in natural language. Foundations of Language 14.247-49.

Simons, MANDY. 2001. On the conversational basis of some presuppositions. Proceedings of Semantics and Linguistic Theory (SALT) 11.431-48.

Simons, Mandy; Judith Tonhauser; David Beaver; and Craige Roberts. 2011. What projects and why. Proceedings of Semantics and Linguistic Theory (SALT) 22.309-27.

Smith, E. Allyn, and KathleEn Currie Hall. 2011. Projection diversity: Experimental evidence. Proceedings of the 2011 ESSLLI Workshop on Projective Content, 156-70.

Spenader, Jennifer. 2002. Presuppositions in spoken discourse. Stockholm: Stockholm University dissertation.

SPENADER, JENNIFER. 2003. Factive presuppositions, accommodation and information structure. Journal of Logic, Language, and Information 12.351-68.

Stalnaker, RoBert C. 1973. Presuppositions. Journal of Philosophical Logic 2.447-57.

Stalnaker, Robert C. 1974. Pragmatic presuppositions. Semantics and philosophy, ed. by Milton K. Munitz and Peter K. Unger, 197-213. New York: New York University Press.

StALNAKer, ROBERT C. 1998. On the representation of context. Journal of Logic, Language and Information 7.3-19.

Stalnaker, Robert C. 2002. Common ground. Linguistics and Philosophy 25.701-21.

StALnAKer, RoBert C. 2008. A response to Abbott on presupposition and common ground. Linguistics and Philosophy 31.539-44.

TONHAUSER, JUDITH. 2006. The temporal semantics of noun phrases: Evidence from Guarani. Stanford, CA: Stanford University dissertation.

TONHAUSER, JUdith. 2007. Nominal tense? The meaning of Guaraní nominal temporal markers. Language 83.4.831-69.

TONHAUSER, JUDITH. 2009. Counterfactuality and future time reference: The case of Paraguayan Guaraní -mo 'ã. Proceedings of Sinn und Bedeutung 13.527-41.

TONHAUSER, Judith. 2010. Is Paraguayan Guaraní a tenseless language? Proceedings of Semantics of Under-represented Languages in the Americas (SULA) 5.227-42.

TONHAUSER, JUDITH. 2011a. The future marker - ta of Paraguayan Guaraní: Formal semantics and cross-linguistic comparison. Tense across languages, ed. by Renate Musan and Monika Rathert, 207-31. Tübingen: Niemeyer.

Tonhauser, Judith. 2011b. Temporal reference in Paraguayan Guaraní, a tenseless language. Linguistics and Philosophy 34.257-303.

Tonhauser, Judith. 2012. Diagnosing (not-)at-issue content. Proceedings of Semantics of Under-represented Languages in the Americas (SULA) 6.239-54.

TONHAUSER, Judith, and ERIKA ColiJn. 2010. Word order in Paraguayan Guaraní. International Journal of American Linguistics 76.2.255-88.

VAN DER SANDT, ROB. 1992. Presupposition projection as anaphora resolution. Journal of Semantics 9.333-77.

van Der Sandt, Rob, and Bart Geurts. 2001. Too. Proceedings of the 13th Amsterdam Colloquium, 180-85.

VelázQuez-CAStillo, Maura. 1995. Noun incorporation and object placement in discourse: The case of Guaraní. Word order in discourse, ed. by Pamela A. Downing and Michael Noonan, 555-79. Amsterdam: John Benjamins.

Velázquez-Castillo, Maura. 1996. The grammar of possession: Inalienability, incorporation and possessor ascension in Guaraní. Amsterdam: John Benjamins.

VelázQuez-Castillo, Maura. 1999. Body-part EP constructions. External possession, ed. by Doris L. Payne and Immanuel Barshi, 77-107. Amsterdam: John Benjamins.

VelÁzQuez-Castillo, MaURA. 2002a. Grammatical relations in active systems: The case of Guaraní. Functions of Language 9.2.133-67.

VelázQuez-CAStillo, Maura. 2002b. Guaraní causative constructions. The grammar of causation and interpersonal manipulation, ed. by Masayoshi Shibatani, 507-34. Amsterdam: John Benjamins.

Velázquez-Castillo, Maura. 2004a. Guaraní (Tupí-Guaraní). Morphology: An international handbook on inflection and word-formation, vol. 2, ed. by Geert Booij, Chris- 
tian Lehmann, Joachim Mugdan, and Stavros Skopeteas, 1421-32. Berlin: Mouton de Gruyter.

Velázquez-Castillo, Maura. 2004b. Serial verb constructions in Paraguayan Guaraní. International Journal of American Linguistics 70.2.187-213.

VON FINTEL, KAI. 2004. Would you believe it? The king of France is back! Presuppositions and truth value intuitions. Descriptions and beyond, ed. by Marga Reimer and Anne Bezuidenhout, 315-41. Oxford: Oxford University Press.

VON FinTel, KAI. 2008. What is presupposition accommodation again? Philosophical Perspectives 22.1.137-70.

von Fintel, KaI, and Lisa Matthewson. 2008. Universals in semantics. The Linguistic Review 25.139-201.

WALKER, RACHEL. 1999. Guaraní voiceless stops in oral versus nasal contexts: An acoustical study. Journal of the International Phonetic Association 29.63-94.

Xue, Jingyang, and Edgar Onea. 2011. Correlation between projective meaning and atissueness: An empirical study. Proceedings of the 2011 ESSLLI Workshop on Projective Content, 171-84.

ZeEvat, HenK. 2000. Discourse particles as speech act markers. LDV Forum: Forum der Gesellschaft für Linguistische Datenverarbeitung (GLDV) 17.1/2.74-91.

Tonhauser and Roberts

222 Oxley Hall, 1712 Neil Ave

Columbus, $\mathrm{OH} 43210$

[judith@ling.osu.edu]

[croberts@ling.osu.edu]

Beaver

CLA 4.304, Mailcode B5100

Austin, TX 78712

[dib@utexas.edu]

Simons

Baker Hall 135

Carnegie Mellon University

Pittsburgh, PA 15213

[simons@andrew.cmu.edu]
[Received 5 July 2011;

accepted with revisions 2 May 2012; accepted 29 November 2012] 